\title{
Performance Improvement of a Low-Power Wind Turbine Using Conical Sections
}

\author{
Janesh N. Mohanan (D), Kumaravel Sundaramoorthy *(D) and Ashok Sankaran \\ Department of Electrical Engineering, National Institute of Technology Calicut, Kerala 673601, India; \\ janeshnm@gmail.com (J.N.M.); ashoks@nitc.ac.in (A.S.) \\ * Correspondence: kumaravel_s@nitc.ac.in
}

check for updates

Citation: Mohanan, J.N.;

Sundaramoorthy, K.; Sankaran, A. Performance Improvement of a Low-Power Wind Turbine Using Conical Sections. Energies 2021, 14, 5233. https://doi.org/10.3390/ en14175233

Academic Editor: Jari Hämäläinen

Received: 16 July 2021

Accepted: 19 August 2021

Published: 24 August 2021

Publisher's Note: MDPI stays neutral with regard to jurisdictional claims in published maps and institutional affiliations.

Copyright: (c) 2021 by the authors. Licensee MDPI, Basel, Switzerland. This article is an open access article distributed under the terms and conditions of the Creative Commons Attribution (CC BY) license (https:// creativecommons.org/licenses/by/ $4.0 /)$.

\begin{abstract}
This paper examines the performance of conical sections (concentrator and diffuser) to improve the energy-recovery prospects of small-scale wind turbines. Detailed simulation studies of the conical sections with convergence angle viz., concentrator, and divergence angle viz., diffuser were conducted using ANSYS Fluent ${ }^{\circledR}$ software. Using simulation data, a trend analysis was conducted, and the empirical equations were derived for calculating the velocity variation and power variation in terms of the convergence/divergence angles. Working prototype models with optimum angles were fabricated for both the diffuser and concentrator. These models were then augmented with a wind turbine coupled with a $100 \mathrm{~W}, 24 \mathrm{~V}$ DC generator and tested to validate the simulation results. Upon analyzing the simulation data, it was found that a maximum velocity variation of $23.3 \%$ was achieved at an angle of $4.5^{\circ}$ for the diffuser, whereas a maximum power variation of $65.1 \%$ was achieved at an angle of $3.6^{\circ}$ for the same diffuser. The aforementioned improvement was achieved by optimizing divergence angle alone. The proposed designs of the diffuser- and concentrator-augmented wind turbine, as well as the empirical equations for calculating the velocity variation and power variation in terms of the divergence and convergence angle, are the major contributions of this article.
\end{abstract}

Keywords: CFD analysis; concentrator; convergent angle; diffuser; divergence angle; wind energy

\section{Introduction}

About $80 \%$ of primary energy demand is met by fossil fuels, and emission during their combustion is the major reason for global warming (GW) and climate change [1]. Further, fossil fuels will be exhausted within a century at their current consumption rates [2,3]. A relentless search for a clean, non-depleting source of energy has finally succeeded through the development of renewable energy sources [4-7]. Some studies suggest that a $100 \%$ renewable energy (RE)-based European Union (EU) power system is feasible by the year 2050 with upgradation of cross-border power transmission capabilities and energyefficiency (EE) improvement measurers [8,9]. To contain global warming below $2{ }^{\circ} \mathrm{C}$, the EU decided in 2011 to reduce greenhouse gas (GHG) emissions by 80-95\% below that of 1990 levels. In the 2016 Paris Agreement, it was decided to limit the temperature rise to $1.5^{\circ} \mathrm{C}$ above pre-industrial levels. These commitments call for drastic reduction of $\mathrm{CO}_{2}$ emissions that can be achieved only through large-scale implementation of RE technologies, EE improvement programs, and carbon capture and storage (CCS) technologies [9].

It is expected that RE will supply two-thirds of the global energy demands by 2050. However, there are major challenges to be addressed before such large-scale adaptation of $\mathrm{RE}$ is possible. RE is distributed in nature, intermittent in availability, and poses serious issues regarding transportability and low energy return on investment (EROI) [10,11]. Among the various RE sources available today, wind is considered as one of the fastestgrowing, most cost-effective, clean sources with the lowest land use intensity [1]. World wind energy output is expected to grow from the 2015 level of 3\% to $16 \%$ of global energy demand by 2050 [12]. 
Horizontal axis wind turbines (HAWTs) are available with rated wind velocities ranging from 10 to $15 \mathrm{~m} / \mathrm{s}$. A 50\% drop in wind velocity results in an $87.5 \%$ drop in the output power of wind turbine (WT) [13]. With HAWTs being so sensitive to wind velocity, grid-connected wind farms across India are confined to few wind corridors. The data in Table 1 are generally used when deciding on the suitability of a site for wind energy. As shown in Figure 1, in India, sites with $10 \mathrm{~m} / \mathrm{s}$ wind velocity are very rare, and most of the commercial HAWTs are operating at a fraction of their rated output. At the same time, wind velocities of the order of $4 \mathrm{~m} / \mathrm{s}$ to $5 \mathrm{~m} / \mathrm{s}$ are abundantly available along coastal lines that stretch over $7500 \mathrm{~km} \mathrm{[14]} \mathrm{and} \mathrm{in} \mathrm{hilly} \mathrm{regions} \mathrm{in} \mathrm{south,} \mathrm{west,} \mathrm{and} \mathrm{central} \mathrm{India.}$

Table 1. Wind speed vs. power-generation suitability in India [15].

\begin{tabular}{cc}
\hline Average Wind Speed $\mathbf{~} / \mathbf{s} \mathbf{~} \mathbf{k m} / \mathbf{h})$ & Suitability for Power Generation \\
\hline $4(15)$ & Not good \\
$5(18)$ & Poor \\
$6(22)$ & Moderate \\
$7(25)$ & Good \\
$8(29)$ & Excellent \\
\hline
\end{tabular}

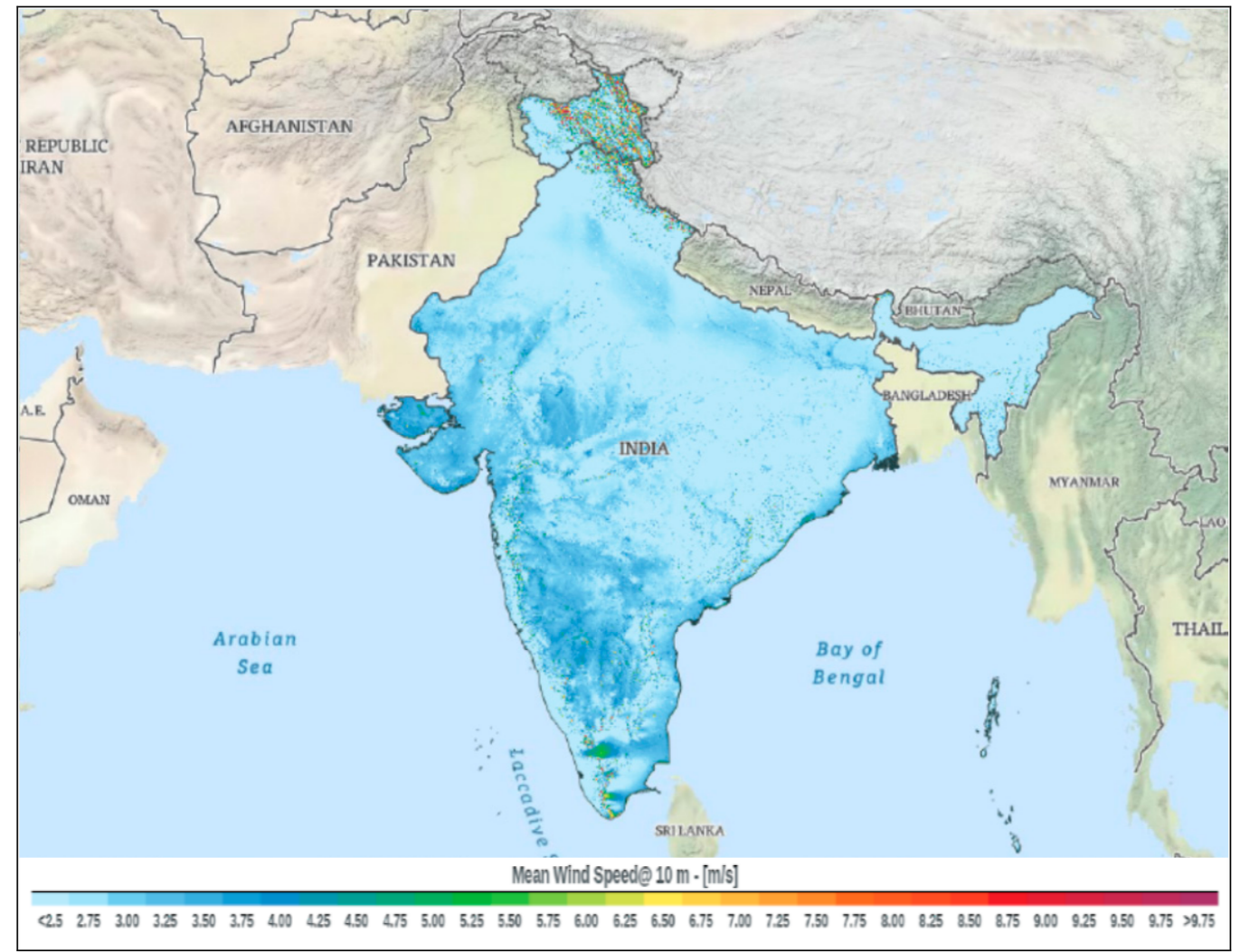

Figure 1. Wind map of India (10 m) from the Global Wind Atlas [16].

\section{Background of the Study}

A conical section is known to improve wind velocity when placed in an open flow of wind. A typical conical section is shown in Figure 2a. The diameter of the conical section varies continuously from the inlet to the outlet. The conical section receives wind at the inlet, and it exits through the outlet. During the flow of wind through the conical section, the wind velocity changes from entry to exit. Depending on the wind flow direction, a conical section can operate in two different modes with entirely different working mechanisms, as shown in Figure 2c (diffuser) and Figure 2d (concentrator). 


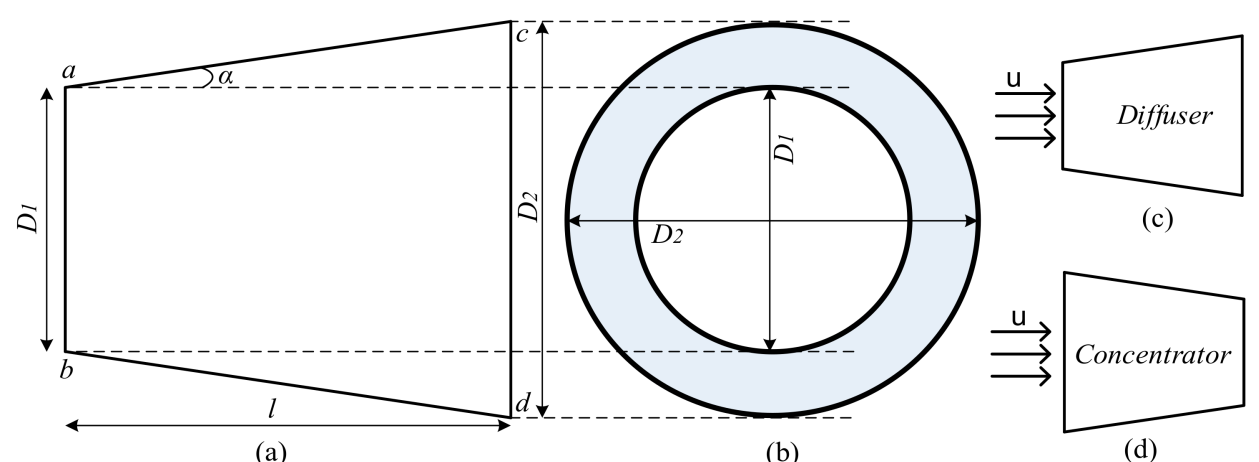

Figure 2. (a,b) Conical section dimensions; (c) diffuser mode; (d) concentrator mode.

Several studies have been reported on different attempts to improve wind velocity for various applications. Abbaspour et al. (2009) studied and reported on velocity amplifications through conical sections in closed wind loops in their environmental wind tunnels (EWTs) design [17]. Matsushima et al. (2006) investigated and reported on the use of flanged diffusers to amplify wind velocity in an open flow. Flow separation by a flanged diffuser, through its internal and external regions, creates a low-pressure region within the diffuser. This low-pressure region induces an accelerated flow through the inlet [18]. In their study using a flanged diffuser, simulation studies were carried out by varying the (i) divergence angle, (ii) diffuser length, and (iii) flange length. They established that the introduction of a flange improved the wind velocity up to a flange height of $0.1 \mathrm{~m}$ (for the model considered), but a further increase of the flange height did not influence the wind velocity. The divergence angle and the length of the diffusor also influenced the wind velocity improvement through a diffuser. However, the paper did not quantify the contributions of the divergence angle, flange height, or diffuser length when acting one at a time.

Later, Kannan et al. (2013) conducted a detailed investigation of the effect of wind velocity on different shapes of splitters placed inside flanged diffusers to develop a suitable flanged diffuser/splitter combination for the wind turbines [19]. This work was a continuation of the work carried out by Matsushima et al. (2006). In 2012, Orosa et al. proposed a non-rotating wind concentrator for concentrating and accelerating the wind velocity for enhancing the performance of vertical axis wind turbines (VAWTs) [20]. In their study, they used a wind concentrator for accelerating wind velocity instead of a flanged diffuser. Gohar et al. (2019) proposed an INVELOX wind power generator system for multiple wind turbines through CFD. They proposed an omnidirectional wind-capturing system, suitable for extracting enhanced wind energy and claiming a better maneuverability of wind turbines utilizing the venturi effect, and integrating multiple wind turbines [21].

Other notable studies reported include an idea presented by Korprasertsak et al. (2015) regarding wind boosters for vertical axis wind turbines. The concept was to accelerate incoming wind using a concentrator (guide vanes) made with curved triangular shapes designed to direct air streams directly toward turbine blades [22]. In [23], the proposed double wind tunnel comprised fixed wind concentrators fitted on either side of a vertical axis wind turbine. In recent years, more efforts have been exerted to predict the wind speed in advance in order to extract more energy from the available wind speed [24]. In most of these studies, the concept was to intervene with the incoming natural wind and amplify its velocity before it reached the turbine blades.

Chipo Shonhiwa et al. (2016) described about 24 studies related to concentrator augmented wind turbines (CAWTs) [25]. This review concluded that a CAWT increases a wind turbine's efficiency. However, this concept is not yet commercialized, as little is known about the working mechanism of the concentrator mentioned by Chipo Shonhiwa et al. The review also highlighted that more study is needed to optimize the incident (convergence) angle, the concentrator length, and the concentrator's frictional losses. 
Vaz JRP et al. (2018) published a detailed mathematical analysis of the effects of diffuser efficiency on wind turbine performance [26]. This study highlighted that when a diffuser was augmented with a wind turbine (WT), it could exceed the Betz limit (59\% sealing on the performance coefficient of a WT). They assessed the impact of a diffuser with an augmentation factor (ratio of turbine efficiency to Betz limit). The unity augmentation factor (Betz limit) corresponded to $74 \%$ diffuser efficiency and $20 \%$ thrust from the diffuser alone. Their study, based on an airfoil cross-section for the diffuser wall, was different from the study in the current paper. A plain cross-section for the diffuser wall was considered in this paper.

Unlike previous studies, the focus of this work is the effect of convergence (divergence) angles on wind velocity, and power when a concentrator (diffuser) is placed in open flow of wind, for the following compelling reasons:

- A flanged diffuser augments rotor diameter significantly, and adds a significant amount of horizontal wind loads on the WT tower and structure. From a practical point of view for a selected rotor, a short length unflanged diffuser with a $4^{\circ}$ divergence angle (proposed in this paper) augments the rotor diameter only marginally.

- Increasing wall length reduces the available rotor-swept area for a given angle. Every $10 \%$ increase of wall length reduces the rotor-swept area by $2.4 \%$ for the $4^{\circ}$ divergence angle proposed in this study. In addition to this, increasing the diffuser length increases the dead weight, the horizontal wind load on the WT tower due to increased effective rotor diameter.

- Accelerating wind flow beyond the rated speed of the wind turbine (usually $10 \mathrm{~m} / \mathrm{s}$ to $15 \mathrm{~m} / \mathrm{s}$ ) is practically meaningless for energy-recovery applications using a HAWT.

- The addition of flanges and extension of the wall length are expected to impart serious disturbances in the trailing wind flow and adversely affect the performance of wind turbines placed downstream.

Hence, this study placed more emphasis on optimizing the performance angle (convergence/divergence angle) and bringing out the empirical relation between the performance angle and the wind turbine output. This study also emphasized understanding the working mechanism of both the diffuser and concentrator.

The Contributions of this work are:

(i). A performance comparison of a concentrator and diffuser of similar dimensions for wind velocity amplification works;

(ii). A simple and logical explanation of the working mechanisms of the concentrator and diffuser;

(iii). Empirical equations for calculating the velocity variations and power variation in terms of performance angles from the open flow of wind;

(iv). An effective solution for tapping into the abundantly available low-velocity wind resources in rural/coastal villages;

(v). By attaining 63\% improvement in energy recovery using a diffuser, this paper reconfirmed the earlier studies that Betz limits can be crossed by augmenting a wind turbine with a diffuser; and

(vi). Having different optimum performance angles and optimum performance values, the diffuser's and concentrator's modes of operation for a conical section are not interchangeable.

This paper is divided into seven sections. Design concepts and a description of the wind velocity amplification are briefly explained under Section 3. Simulation studies of the proposed conical sections and the results and discussions are elaborated in Sections 4 and 5 respectively. The testing of the prototype model and the conclusions are discussed in Sections 6 and 7, respectively.

\section{Design Concepts and Description of the Wind Velocity Amplification}

To identify the optimum performance angle of the conical section, a detailed analysis of the conical sections in both modes of operation was carried out. The one-meter conical 
section used in this study was designed with a one-meter diameter at the larger end $\left(D_{2}\right)$ and a one-meter length (1), as detailed in Figure 2. For the analysis, the angle $\alpha$ was varied from $2^{\circ}$ to $16^{\circ}$ with a step size of $2^{\circ}$ for creating conical section models. The diameter at the smaller end $\left(D_{1}\right)$ of the conical section depended on angle $\alpha$ (the divergence angle for the diffuser and the convergence angle for the concentrator).

In the diffuser mode of operation, wind flow diffuses from the lower cross-sectional end $p-q$ towards the larger cross-sectional end $r$-s, as illustrated in Figure 3. This flow creates a low-pressure region within the conical section that extends beyond the outlet. This low-pressure region attracts more wind inside the conical section, and significantly accelerates the wind flow through the inlet of the diffuser. A wind turbine, when placed within the conical section, close to the inlet, experiences an enhanced wind velocity across its blades.

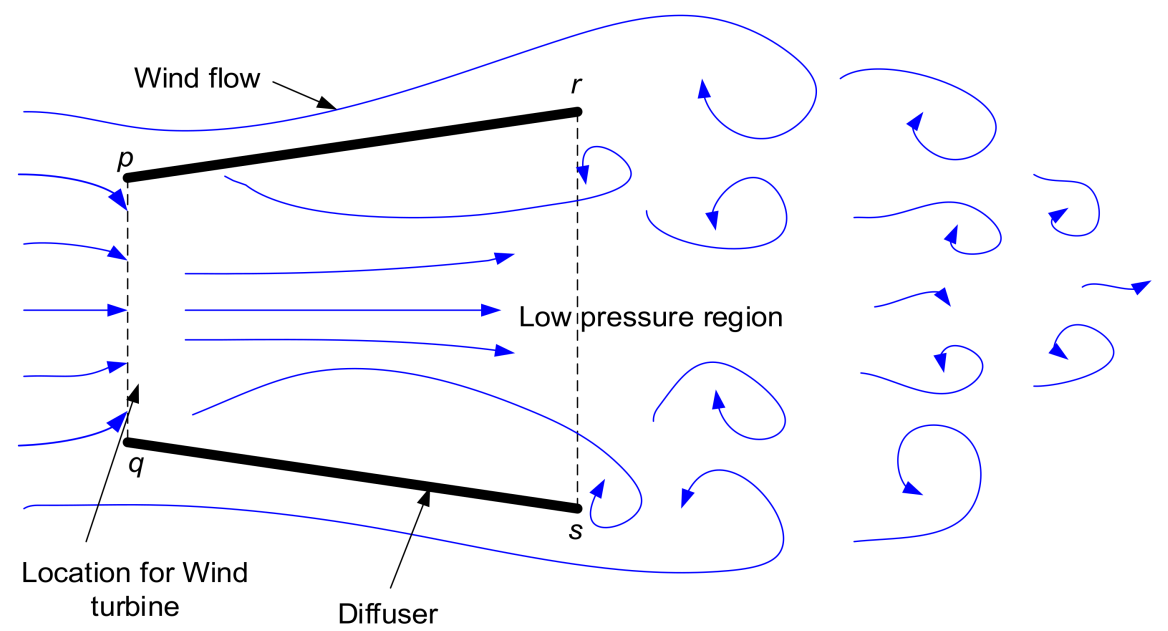

Figure 3. Wind flow through the diffuser.

In concentrator mode, wind passes through the conical section from the larger crosssectional end $r$-s towards the smaller cross-sectional end $p-q$. Throughout the wind flow, the wind velocity changes within the concentrator, as illustrated in Figure 4.

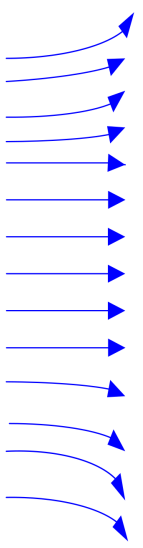

Approaching wind

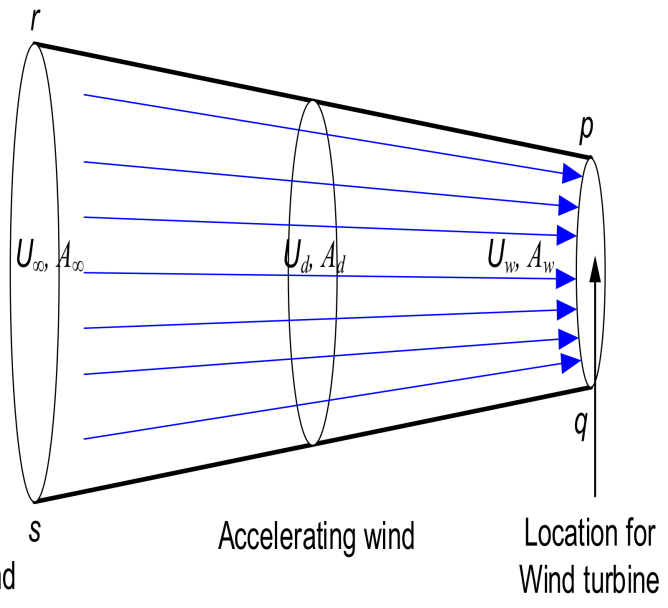

Wind turbine

Figure 4. Wind flow through the concentrator.

For the operating wind velocity, air is incompressible, as the Mach number is far less than 0.3 [27]. Considering there are no losses of air, the mass flow rate is conserved at every cross-section of the conical section, which can be expressed as $A_{\infty} U_{\infty}=A_{d} U_{d}=A_{w} U_{w}$. Here, $A$ and $U$ are the cross-sectional area and the random upstream velocity respectively, and the subscripts $\infty, d$, and w denote each at the upstream, random, and downstream, 
respectively [12]. As seen, area and velocity are inter-related and proportional inversely to each other so that their product remains constant. Thus, the area being minimal at the exit of the concentrator, wind velocity is maximum. If the wind turbine is placed just outside the exit of the concentrator as shown, the turbine experiences enhanced wind velocity across its blades.

\section{Simulation Studies Using CFD Platform}

Both the concentrator and diffuser designs were developed and simulated using the 'ICEM CFD', 'FLUENT' and 'CFX' packages provided with the ANSYS Fluent ${ }^{\circledR}$ software (ver. 2019 R3). The physical domain considered for the simulation is shown in Figure 5. A diffuser with a $1 \mathrm{~m}$ length, $1 \mathrm{~m}$ diameter (at the larger end), and $16^{\circ}$ divergence angle was placed at the center of a large hypothetical wind tunnel with a $41 \mathrm{~m}$ length and $20 \mathrm{~m}$ diameter, as shown. A uniform wind with different velocities was applied at the inlet of the tunnel. A large tunnel was selected to ensure sufficient time and distance to establish a laminar flow of wind at the inlet of the small diffuser. The interior of the wind tunnel and the interior of the conical section were meshed by the tetrahedral method, as shown in Figure 6.

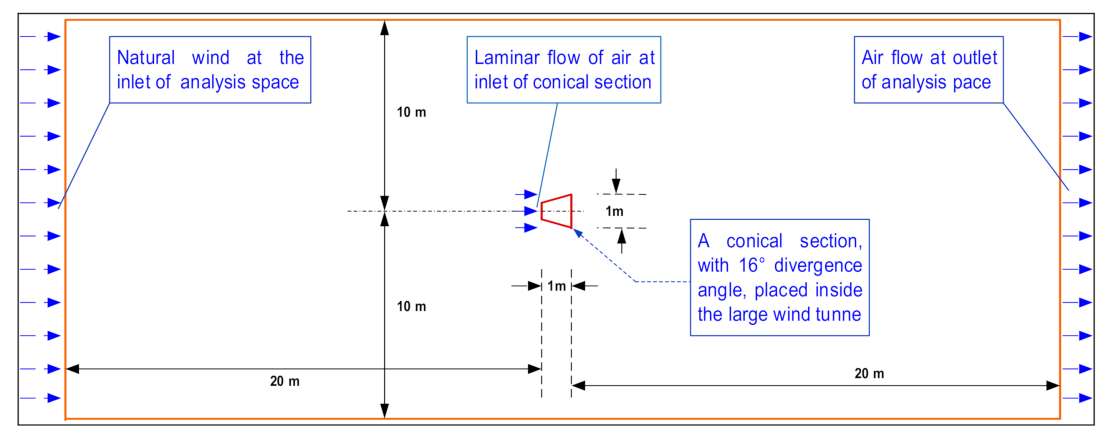

Figure 5. The physical domain considered for the simulation.

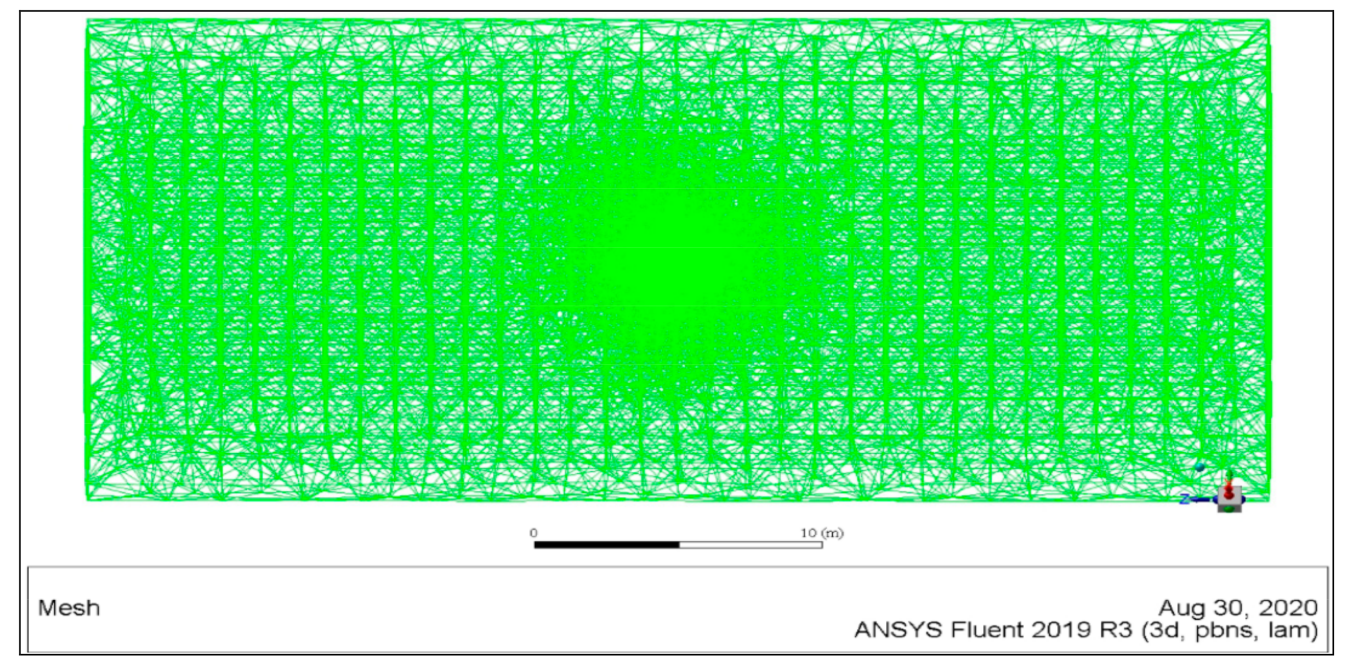

Figure 6. The physical domain considered for the simulation after meshing.

Simulations were carried out under steady-state conditions. Initially, the simulations were conducted using the $\mathrm{k}-\varepsilon$ turbulent model, and later with the laminar viscous model, for the following reasons. Since the physical domain considered was very large, the turbulent intensity of the flow approaching the diffuser/concentrator was negligible, and the surface roughness effects were also considered to be negligible. Therefore, it was noted that the turbulence features in the flow field were insignificant in the present simulations. Further, this fact is also noted in the comparison table (Table 2) of simulation studies carried out with turbulent and laminar flow models, where the velocity attained using both the 
models were almost similar. In addition, since the grid size considered for the simulations was very large $(461,534$ cells), a laminar viscous model helped to reduce the computational power and time.

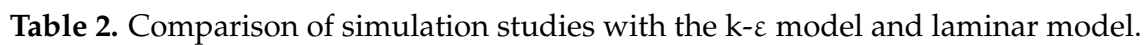

\begin{tabular}{|c|c|c|c|c|c|}
\hline Conical Section & $\begin{array}{l}\text { Inlet Wind } \\
\text { Velocity } \\
(\mathrm{m} / \mathrm{s})\end{array}$ & 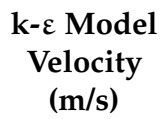 & $\begin{array}{c}\text { Laminar } \\
\text { Model } \\
\text { Velocity }(\mathrm{m} / \mathrm{s})\end{array}$ & $\begin{array}{c}\text { Velocity } \\
\text { Variation } \\
(\mathrm{m} / \mathrm{s})\end{array}$ & $\begin{array}{c}\text { Velocity } \\
\text { Variation \% }\end{array}$ \\
\hline Diffuser, div. angle $4^{\circ}$ & 7 & 8.8971 & 8.7750 & 0.1221 & 1.3724 \\
\hline Diffuser, div. angle $6^{\circ}$ & 7 & 8.5500 & 8.5396 & 0.0104 & 0.1216 \\
\hline Diffuser, div. angle $10^{\circ}$ & 7 & 8.4232 & 8.1799 & 0.2433 & 2.8885 \\
\hline $\begin{array}{l}\text { Concentrator, con. } \\
\text { angle } 4^{\circ}\end{array}$ & 9 & 8.5974 & 8.5449 & 0.0525 & 0.6106 \\
\hline $\begin{array}{l}\text { Concentrator, con. } \\
\text { angle } 6^{\circ}\end{array}$ & 9 & 8.9436 & 8.8861 & 0.0575 & 0.6429 \\
\hline $\begin{array}{l}\text { Concentrator, con. } \\
\text { angle } 10^{\circ}\end{array}$ & 9 & 9.6436 & 9.6263 & 0.0173 & 0.1794 \\
\hline
\end{tabular}

A grid independence test was conducted to ensure the accuracy of the solutions obtained. Details of the test results, shown in Table 3, indicated the percentage relative error was negligible.

Table 3. Grid independence test results.

\begin{tabular}{cccc}
\hline Model & Number of Cells & Velocity $(\mathbf{m} / \mathbf{s})$ & Relative \% Error \\
\hline & 425,563 & 8.7993 & 0.0028 \\
Conical section & 461,534 & 8.7750 & 0.0023 \\
& 492,627 & 8.7546 & 0.0010 \\
& 546,073 & 8.7455 & 0.0008 \\
\hline
\end{tabular}

Similarly, seven more models were created using the CFD platform, with divergence angles of $2^{\circ}, 4^{\circ}, \ldots, 14^{\circ}$. Thus, a total of eight conical sections were created, with divergence angles varying from $2^{\circ}$ to $16^{\circ}$ with a step size of $2^{\circ}$. During the simulation study, each diffuser was placed at the center of the large tunnel one at a time, and the simulation was conducted for eight different inlet wind velocities $(1 \mathrm{~m} / \mathrm{s}$ to $15 \mathrm{~m} / \mathrm{s}$ with a step size of $2 \mathrm{~m} / \mathrm{s}$ ). Thus, a total of 64 simulations were carried out for the eight conical sections while using them in the diffuser mode, and the results were carefully analyzed to establish their individual characteristics and common trend.

Upon completion of the above simulation, each of the eight models was simulated again in the concentrator mode by placing them in the same large wind tunnel and subjecting each one to eight different inlet wind velocities (i.e., $1 \mathrm{~m} / \mathrm{s}$ to $15 \mathrm{~m} / \mathrm{s}$ with a step size of $2 \mathrm{~m} / \mathrm{s}$ ). Thus, another 64 simulations were carried out in the concentrator mode, and the results were carefully analyzed to establish their individual characteristics and trend.

\subsection{Boundary Conditions}

General CFD parameters used for the simulation are given in Table 4. Simulations were carried out by varying the inlet velocities. Under boundary conditions, all walls were set as a 'stationary wall', with a 'no-slip' shear condition. The inlet was set as a 'velocity-inlet' with reference frame: absolute, initial gauge pressure: 0 pascal. The outlet was set as a 'pressure outlet' with gauge pressure: 0 pascal; and backflow pressure specified as 'total pressure' normal to the boundary. Fluids within the concentrator (diffuser) and wind tunnel were set as 'interior', as shown. 
Table 4. General CFD parameters.

\begin{tabular}{ll}
\hline \multicolumn{1}{c}{ Parameters } & \multicolumn{1}{c}{ Value } \\
\hline Solver & Pressure-based \\
Velocity formulation & Absolute \\
Time & Steady \\
Viscous model & k-epsilon (2 eqn.) \\
Report type & Area-weighted average \\
Convergence conditions & All conditions were met \\
Initialization methods & Hybrid initialization \\
Number of iterations & 2500 \\
\hline
\end{tabular}

\subsection{Simulation of Concentrator in CFD Platform}

Using the ICEM CFD software, concentrator models were created, and detailed simulation studies were conducted to assess the performance of the concentrator at various wind velocities. The variations of pressure and velocity contours within the wind tunnel, where the concentrator was placed, are shown in Figure 7, when subjected to $9 \mathrm{~m} / \mathrm{s}$ wind velocity. As shown in Figure 7a, the pressure contour was uniform within the wind tunnel, except for the area shown as enclosed around the concentrator in Figure $7 \mathrm{~b}$, and the walls of wind tunnel.

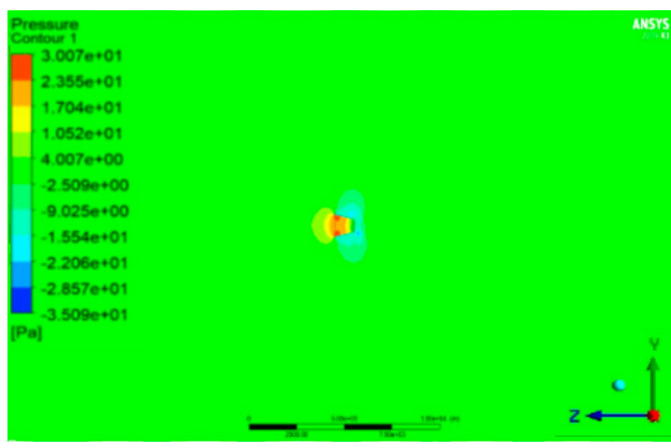

(a)

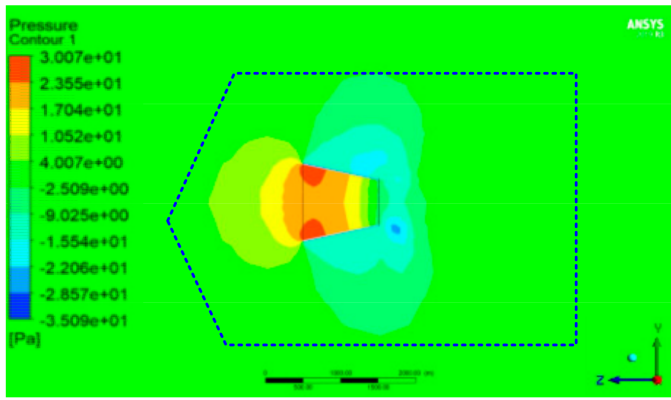

(b)

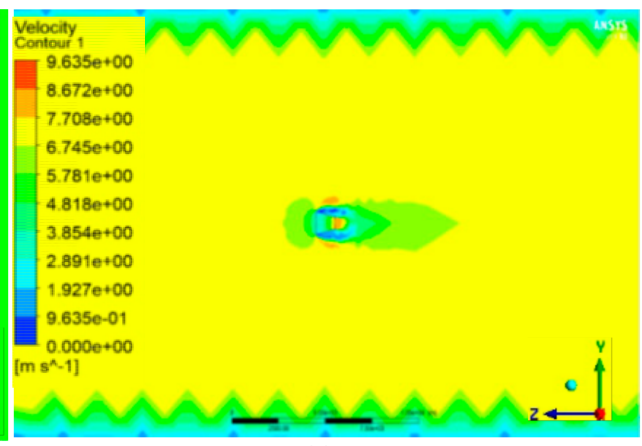

(c)

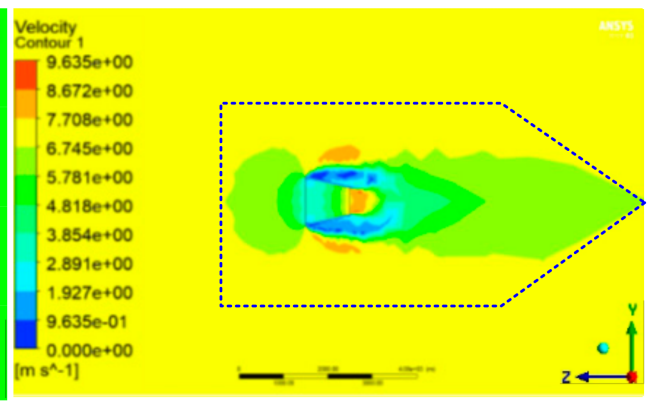

(d)

Figure 7. Contour around and within the concentrator: (a) pressure contour; (b) pressure contour (enlarged view); (c) velocity contour; (d) velocity contour (enlarged view).

As the wind approached the area close to conical section inlet, a positive pressure built up near the conical section inlet. This elevated pressure progressively increased towards the inlet of the conical section, and continued within the conical sections to some extent. Beyond that point, the pressure gradually was reduced until the wind reached the outlet of the conical section. Outside the conical section outlet, there was a further reduction in pressure. There was another low-pressure region created outside and around the outer surface of conical section. This low-pressure region spanned from the inlet of the conical section and extended beyond the outlet region, as shown in Figure 7a,b.

Figure $7 \mathrm{c}, \mathrm{d}$ illustrate the corresponding velocity contours to that of the pressure contours shown in Figure 7a,b. There was a clear one-to-one correlation between the pressure 
and velocity contours. Owing to the formation of a positive-pressure region at the inlet and negative-pressure regions around the concentrator, a part of the incoming streamlines went around the concentrator without entering it. This slowed down the incoming streamlines before entering the inlet of the concentrator. However, those streamlines that entered the concentrator were accelerated within the concentrator due to successive negative-pressure regions created inside the concentrator, and maintained the mass flow rate.

\subsection{Simulation of Diffuser in CFD Platform}

Similar to the simulation studies conducted on the concentrators, different diffuser models were created in the ICEM CFD platform. A detailed simulation study was conducted to assess the performance of the diffusers over a range of wind velocities. The variations of pressure and velocity contours within the wind tunnel, where the diffuser was placed, when subjected to $5 \mathrm{~m} / \mathrm{s}$ wind velocity, are shown in Figure 8. Figure 8a shows that the pressure contour was uniform, except for the enclosed area and close to the walls of the wind tunnel. As the wind approached the inlet of the diffuser, there was a build-up of negative pressure. The pressure further decreases inside the diffuser and close to the outlet of diffuser, and there were few pockets of extremely low-pressure regions created. Beyond this area, the pressure gradually increased until the it matched the rest of the tunnel. Obviously, this low-pressure region sucked more air inside the conical section and accelerated the airflow further. It also can be seen in Figure 8a that there was a high-pressure ring around the diffuser's inlet (yellow color). This higher-pressure ring aided in diverting incoming streamlines through the inlet of the diffuser. Such a diverting effect further enhanced the area average flow velocity through the inlet of the diffuser.

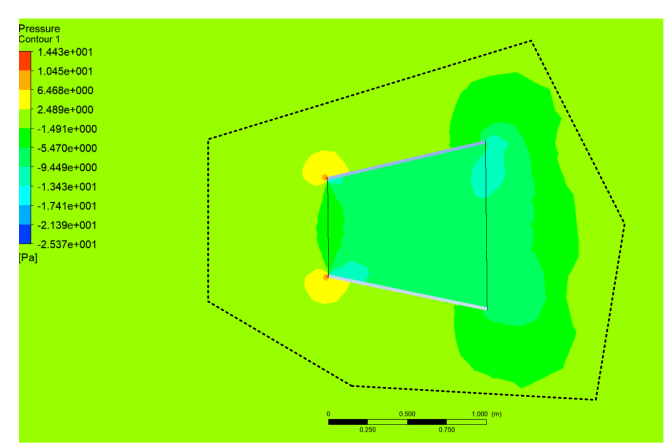

(a)

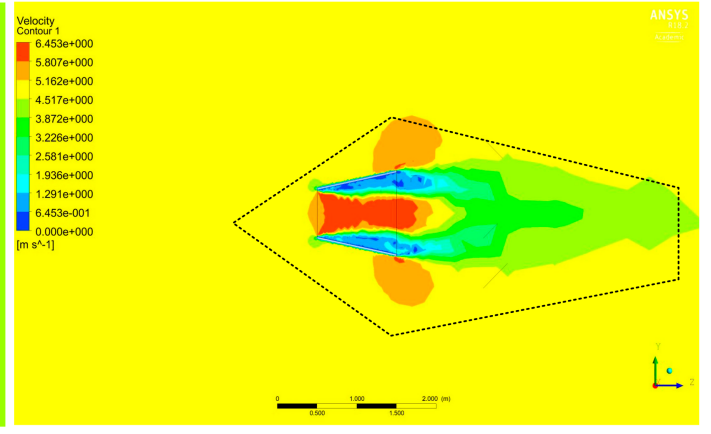

(b)

Figure 8. Contours around and within the diffuser: (a) pressure; (b) velocity.

Figure $8 \mathrm{~b}$ illustrates the corresponding velocity contours to that of the pressure contours shown in Figure 8a. There was a clear one-to-one correlation between the pressure and velocity contours. It is clear from Figure 8 that the flow velocity was maximum and consistent at a region inside the conical section, close to the inlet.

\subsection{Wind Turbine}

Wind power, $P$, which is a function of wind velocity, $V$, and rotor-swept area (limited to the concentrator's outlet area), $A$, is expressed in Equation (1). It may also be noted that the concentrator's outlet area $(A)$ successively decreases with increasing values of $\alpha_{c}{ }^{\circ}$.

$$
P=\frac{1}{2} \rho A V^{3} C_{p} \eta
$$

where $P=$ mechanical power developed by the wind turbine in watts, $V=$ wind velocity in $\mathrm{m} / \mathrm{s}, A=$ rotor swept are in $\mathrm{m}^{2}, \rho=$ air density $\mathrm{kg} / \mathrm{m}^{3}, C_{P}=$ performance coefficient of turbine (dimension less), and $\eta=$ mechanical efficiency of the wind turbine.

Since a WT acts as a semi-permitting wall with resistance to the flow, a portion of the incoming wind passes around the rotor without passing through the rotor. From this 
behavior, Betz established that the theoretical maximum power that a WT can recover is limited to $59 \%$. However, in practice, only about $40 \% C_{P}$ is achievable, as the actual wind is compressible, non-homogenous, and unsteady, with frictional losses.

Wind turbines do not operate before their cut-in wind speed (up to $3.4 \mathrm{~m} / \mathrm{s}$ depending on their design) is attained, and close to cut-in speed, their power recovery rate is very low. In India, up to $5 \mathrm{~m} / \mathrm{s}$ wind speeds are considered 'poor' for energy recovery, and $8 \mathrm{~m} / \mathrm{s}$ wind speeds are considered 'excellent' (Table 1). Improving wind speeds with conical sections is equivalent to bringing down the cut-in speed and improving the power coefficient of a WT.

\section{Results and Discussions}

Simulation data obtained for both the concentrator and diffuser were processed separately to understand their individual performance trends, and then compared to weigh their suitability in wind speed improvement applications.

\subsection{Performance Analysis of the Concentrator}

Wind velocity variation through the concentrator was simulated for different convergence angles $\left(\alpha_{c}{ }^{\circ}\right)$ and different inlet wind velocities to establish the performance trends. The effects of variation of $\alpha_{c}$ on wind velocities and recoverable power from wind that passes through concentrators are shown in Figure 9. For every $\alpha_{c}$, eight different wind velocities (area average) were applied at the inlet of the wind tunnel, and the resultant area average wind velocities were measured at the outlet of the concentrator. The difference between these applied and resultant wind velocities were expressed as a percentage of the applied velocity (velocity variation $\%$ ). For every $\alpha_{c}$, a corresponding velocity variation $\%$ (both positive and negative) was plotted on the graph shown in Figure 9a.

Further, for every $\alpha_{c}$, power carried by the wind was calculated at the inlet of the tunnel (with the applied wind velocity and an area equal to the inlet area of the concentrator) and the corresponding resultant power carried by the wind at the outlet of the concentrator (using the resultant wind velocity and available area at the concentrator outlet). Both velocities involved were area average velocities. The difference between the inlet power and resultant power was expressed as a percentage of the inlet power (power variation \%). For every $\alpha_{c}$, eight different inlet velocities were applied, and the corresponding power variations \% (both positive and negative) were plotted on the graph shown in Figure $9 \mathrm{~b}$. The power variation (\%) with respect to wind velocity for each convergence angle is shown in Figure 9c, which clearly indicates that optimum power angle was between $10^{\circ}$ and $12^{\circ}$.

For the concentrators considered, at lower values of $\alpha_{c}$; i.e., below $6^{\circ}$, the resultant wind velocity was lower than the inlet wind velocity, as shown in Figure 9 a. As $\alpha_{c}$ increased from zero, the resultant wind velocity decreased and reached its negative peak at around $3.8^{\circ} \alpha_{c}$. Thereafter, the resultant wind velocity steadily increased, and reached its positive peak at around $10.8^{\circ} \alpha_{c}$. Beyond $10.8^{\circ} \alpha_{c}$, the resultant wind velocity exhibited a decreasing trend again. 


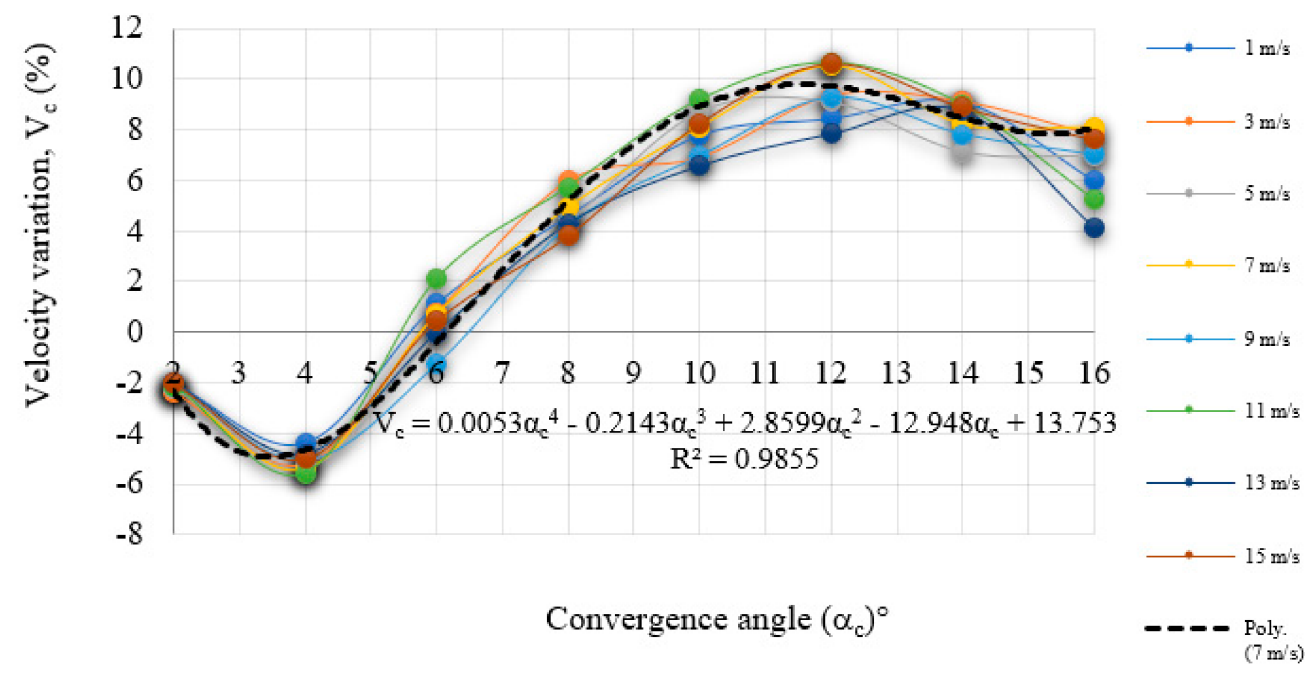

(a)

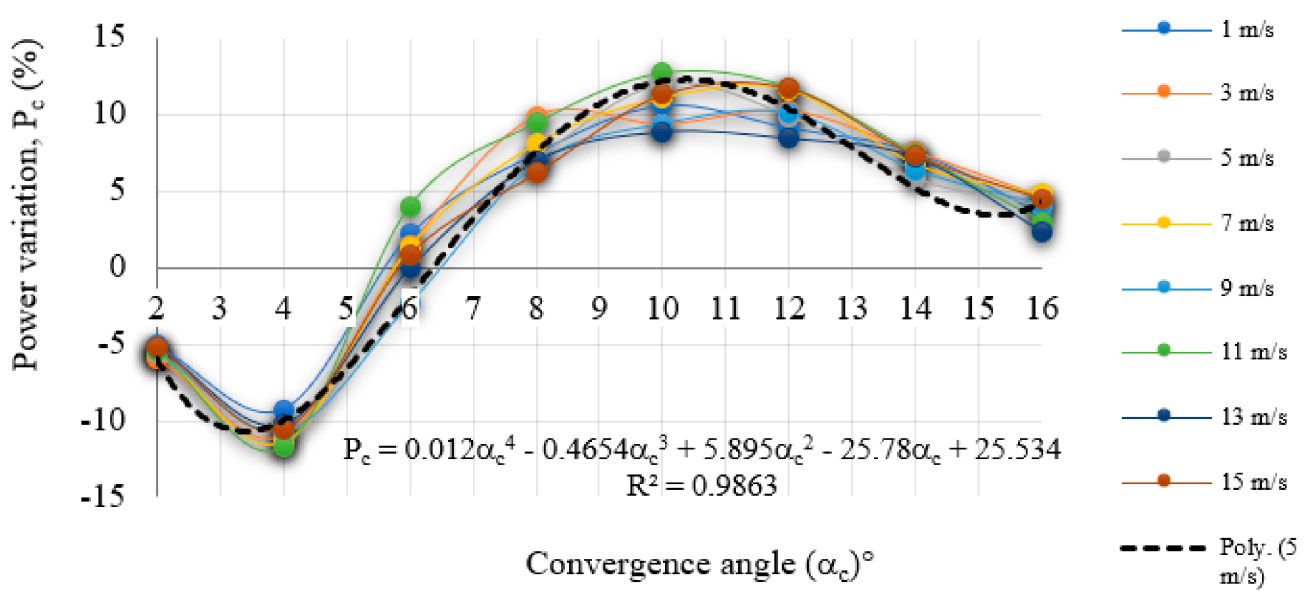

(b)

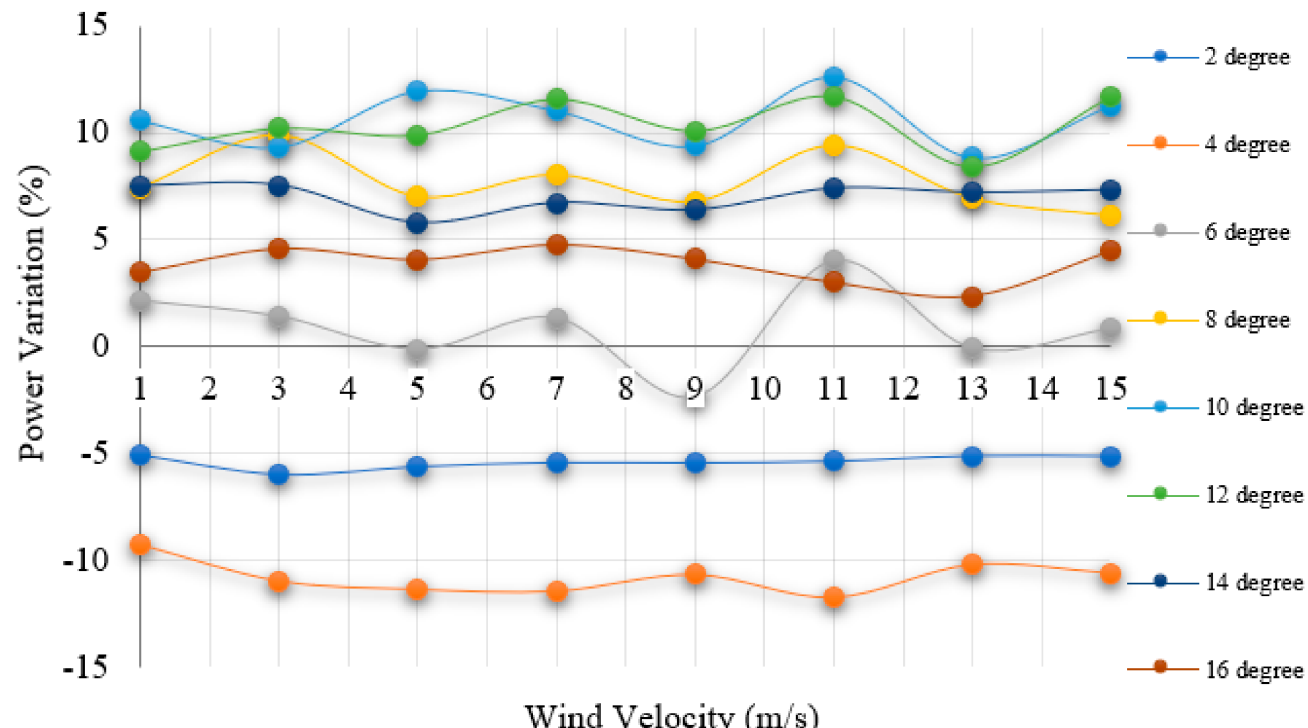

(c)

Figure 9. Effect of $\alpha_{c}$ on: (a) velocity variation, $\mathrm{V}_{\mathrm{c}} \%$; (b) power variation, $\mathrm{P}_{\mathrm{c}} \%$, for a concentrator; (c) power variation $\%$ with respect to the convergence angle. 


\subsection{Performance Analysis of the Diffuser}

Similar to the concentrator, the wind velocity variation through the diffuser was also simulated with different divergence angles $\left(\alpha_{d}{ }^{\circ}\right)$ and different inlet wind velocities to establish the performance trends. Figure 10 shows the variations in wind velocities and the corresponding effects on recoverable power from winds that passed through diffusers with different $\alpha_{\mathrm{d}}$.

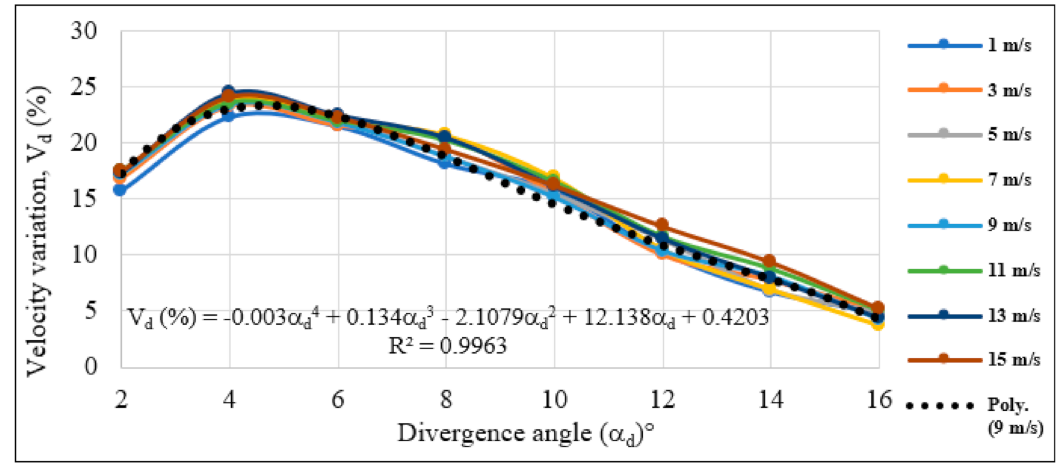

(a)

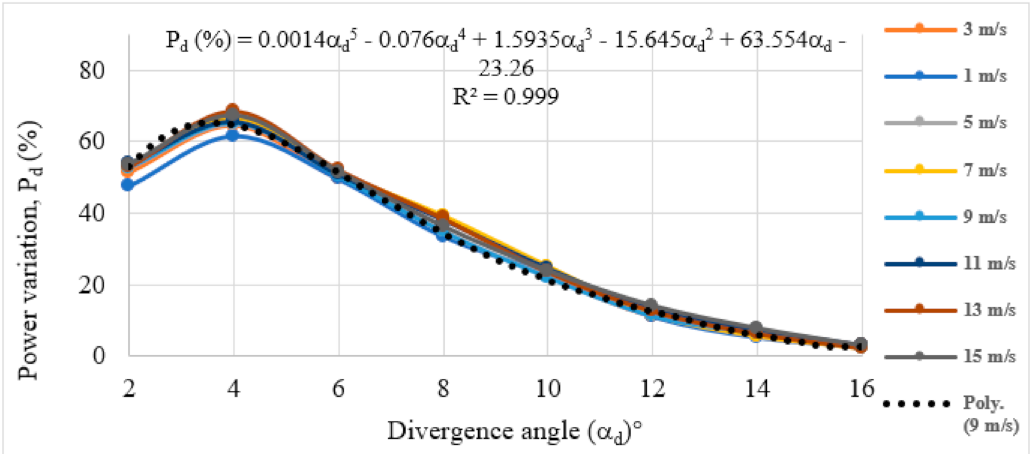

(b)

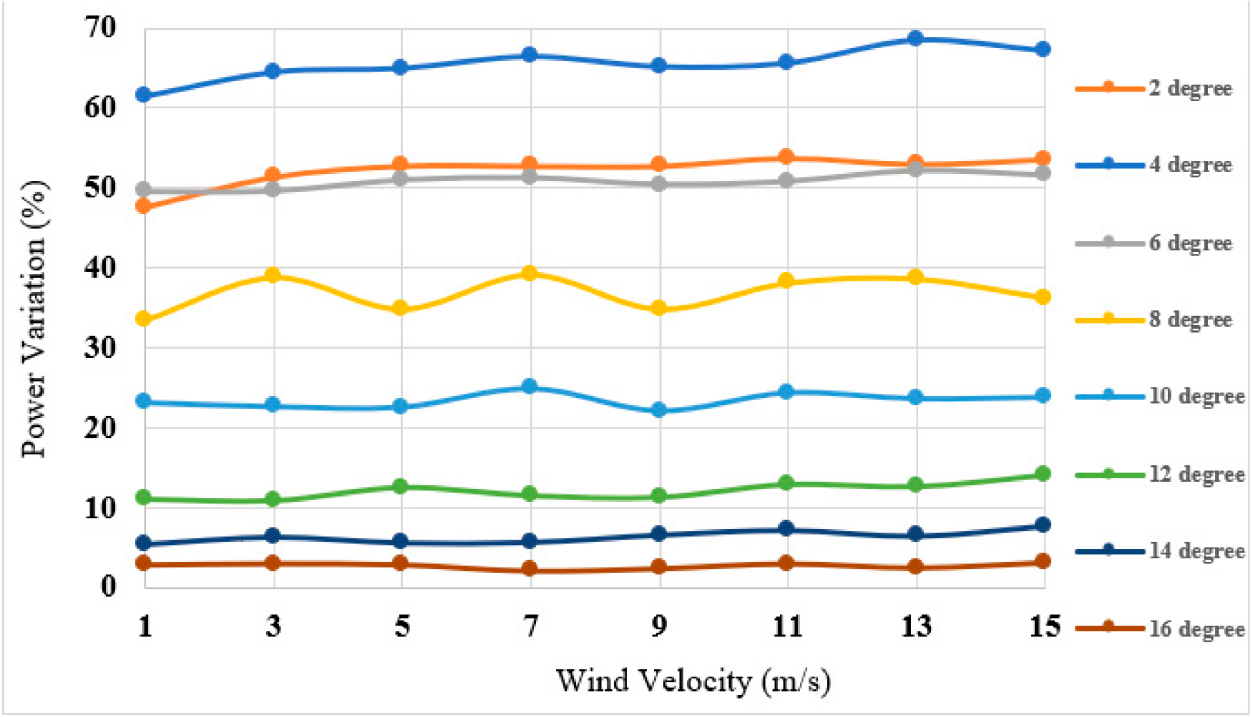

(c)

Figure 10. Effect of $\alpha_{d}$ on: (a) velocity variation, $V_{d} \%$; (b) power variation, $P_{d} \%$, for a diffuser; (c) power variation (\%) with respect to wind velocity for different divergence angles. 
For every $\alpha_{d}$, different wind velocities (area average) were applied at the inlet of the tunnel, and the resultant wind velocities were measured (area average) at the inlet of the diffuser. The difference between these applied and resultant velocities were expressed as a percentage of applied velocity (velocity variation \%). Both velocities involved were the area average. For every $\alpha_{d}$, the velocity variation $\%$ was plotted on the graph shown in Figure 10a.

Further, for every $\alpha_{d}$, the power carried by the wind was calculated at the inlet of the wind tunnel (for an area equal to the outlet area of the diffuser), and the corresponding resultant power developed by the wind at the inlet of the diffuser was calculated using Equation (1). It may also be noted that the diffuser's inlet area (A) decreased with an increasing $\alpha_{\mathrm{d}}$. The difference between these applied powers (wind tunnel inlet power) and resultant power (diffuser inlet power) were expressed as a percentage of the applied power. For every $\alpha_{d}$, eight different inlet velocities were applied, and the corresponding power variations \% were plotted on the graph shown in Figure 10b. Figure 10c indicates the power variation (\%) with respect to wind velocity for different divergence angles.

For the diffuser considered, as the $\alpha_{\mathrm{d}}$ increased from zero, the resultant wind velocity increased and reached its positive peak at around $4.2^{\circ} \alpha_{\mathrm{d}}$. Thereafter, the resultant wind velocity decreased, as illustrated in Figure 10a.

\subsection{Understanding the Workings of Conical Sections}

Conical sections in either concentrator mode or diffuser mode work using a different mechanism, as explained below. The major parameters that influence their performance are their respective converging/diverging angles, wall length, and turbulence in the incoming flow. Surface roughness seems to have an insignificant role in the performance of the conical section. For the practical considerations explained earlier, feasible fixed wall length conical sections were used in this study. The possibility of turbulence in the incoming wind was eliminated by placing the conical sections within a large wind tunnel for simulation, as explained above.

Concentrator: As seen in Figure 9, the velocity improvement was negative up to a convergence angle of about $6^{\circ}$. Thereafter, the velocity increased, and the optimum wind velocity was somewhere close to a convergence angle of $11^{\circ}$. Beyond $11^{\circ}$, the velocity improvement began dropping. This behavior of the concentrator in the open flow of wind is explained below.

Up to a $6^{\circ}$ convergence angle, the wind concentrator effect (ability of the inlet pressure to push wind through the narrow outlet) was negligible, as sufficient pressure was not created at the inlet of the concentrator to overcome resistance to wind flow through the narrow outlet. At the same time, the wind flow recognized the concentrator as an obstacle in the direction of the wind flow. Between convergence angles of $6^{\circ}$ and $11^{\circ}$, the concentrator effects took the upper hand over resistance to flow. Beyond $11^{\circ}$, resistance to wind flow took the upper hand as the flow nozzle (outlet) became narrower. The entire phenomenon was an equilibrium between pressure developed at the inlet of the concentrator and resistance to flow developed at the outlet of the concentrator. Interestingly, for a given inlet wind speed, both the pressures developed at the inlet and resistance to wind flow at the outlet were related to the convergence angle of the concentrator.

Diffuser: As seen in Figure 10, the velocity improvement was always positive for all the divergence angles tested. The optimum wind velocity was somewhere close to a divergence angle of $4^{\circ}$. Beyond $4^{\circ}$, the velocity improvement began decreasing. This phenomenon is explained below.

Below a $2^{\circ}$ divergence angle, the diffuser effect (ability of the diffuser to create wind flow separation and resultant low pressure within the diffuser) was low, and the wind flow had difficulty passing through the narrow inlet. Up to a $4^{\circ}$ divergence angle, the diffuser effect took the upper hand over resistance to flow through the narrow inlet, as increasingly low pressure was created within due to the flow separation. Close to a $4^{\circ}$ divergence angle, the diffuser's output reached its optimum for the diffuser design considered. Beyond a $4^{\circ}$ 
divergence angle, resistance to wind flow began taking the upper hand as the inlet nozzle was narrowed. This phenomenon was also an equilibrium between the resistance to flow at the inlet of the diffuser and the low pressure created within the diffuser, both of which were functions of the divergence angle of the diffuser for a given wind speed.

\subsection{Trend Analysis of the Conical Section-Velocity Improvement}

The performance trends of the concentrator used for velocity and power improvement are also shown in Figure 9. As discussed previously, the resultant wind velocity is a function of the $\alpha_{c}$. A trend analysis was conducted with a curve-fitting method for the concentrator, and the best-fit curve was a 4th-degree polynomial of Equation (2) for its velocity variation. Power variation through the concentrator can also be expressed in terms of $\alpha_{c}$, as given in Equation (3). In both cases, a 4th-degree polynomial was selected based on the goodness-of-fit test results. Both polynomials fit with an $R^{2}$ value of $98.6 \%$, as shown in Figure 9.

$$
\begin{gathered}
\mathrm{V}_{\mathrm{c}}=0.0053 \alpha_{\mathrm{c}}{ }^{4}-0.2143 \alpha_{\mathrm{c}}{ }^{3}+2.8599 \alpha_{\mathrm{c}}{ }^{2}-12.948 \alpha_{\mathrm{c}}+13.753 \\
\mathrm{P}_{\mathrm{c}}=0.012 \alpha_{\mathrm{c}}{ }^{4}-0.4654 \alpha_{\mathrm{c}}{ }^{3}+5.895 \alpha_{\mathrm{c}}{ }^{2}-25.78 \alpha_{\mathrm{c}}+25.534
\end{gathered}
$$

Similarly, the performance trends of the diffuser used for velocity and power improvement is shown in Figure 10. As already discussed, the resultant variations of wind velocity and power are functions of $\alpha_{\mathrm{d}}$. A trend analysis was conducted with a curve-fitting method for the diffuser, and the best-fit curve was a 4 th-degree polynomial for velocity variation (Equation (4)), and a 5th-degree polynomial for power variation (Equation (5)), as given below. A 4th-degree polynomial was selected for the velocity variation, and a 5 th-degree polynomial was selected for power variation based on the goodness-of-fit test results. Both polynomials fit, with $R^{2}$ values of $99.6 \%$ and $99.9 \%$, respectively, as shown in Figure 10.

$$
\begin{gathered}
V_{d}=-0.003 \alpha_{d}^{4}+0.134 \alpha_{d}^{3}-2.1079 \alpha_{d}^{2}+12.138 \alpha_{d}+0.4203 \\
P_{d}=0.0014 \alpha_{d}^{5}-0.076 \alpha_{d}^{4}+1.5935 \alpha_{d}^{3}-15.645 \alpha_{d}^{2}+63.554 \alpha_{d}-23.26
\end{gathered}
$$

\subsection{Optimization of Velocity and Power}

The trend analysis conducted on the concentrator revealed that the optimum velocity amplification and optimum power recovery did not occur at the same convergence angles. This was because power is dependent on both $V^{3}$ and $A$. While velocity increases with convergence/divergence angle, the area decreases. In addition, the variation of velocity, as well as the area with respect to the convergence (or divergence) angle, follow nonlinear paths. Figure 11 shows a comparison of the diffuser and concentrator at their respective optimum conditions for both velocity and power, which are again summarized in Table 5.

Table 5. Optimum results.

\begin{tabular}{ccccc}
\hline \multirow{2}{*}{ Conical Section } & \multicolumn{2}{c}{ Velocity } & \multicolumn{2}{c}{ Recoverable Power } \\
\cline { 2 - 5 } & $\begin{array}{c}\text { Optimum Velocity } \\
\text { Variation \% }\end{array}$ & $\begin{array}{c}\text { Optimum Velocity } \\
\text { Angle }\end{array}$ & $\begin{array}{c}\text { Optimum Power } \\
\text { Variation \% }\end{array}$ & $\begin{array}{c}\text { Optimum Power } \\
\text { Angle }\end{array}$ \\
\hline Concentrator & 9.8 & 11.5 & 12.3 & 10.5 \\
Diffuser & 23.3 & 4.5 & 65.1 & 3.6 \\
\hline
\end{tabular}




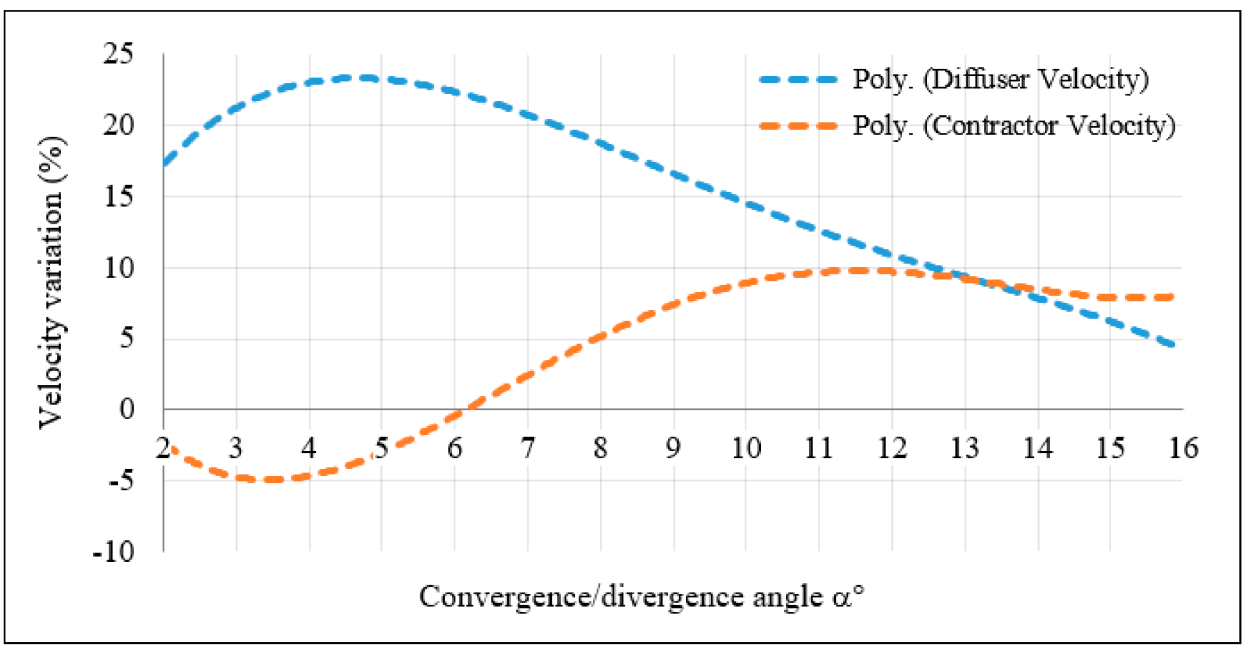

(a)

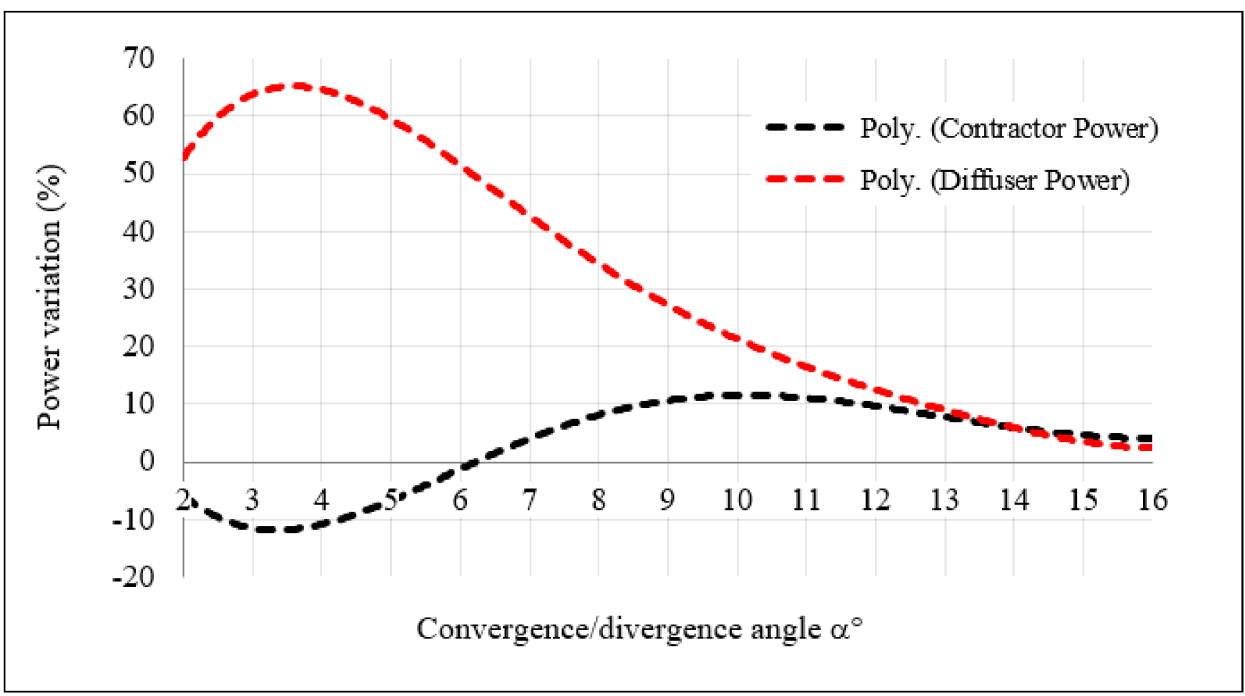

(b)

Figure 11. (a) The optimum velocity variation and (b) optimum power variation for the conical sections.

\section{Fabrication of the Experimental Prototypes of Conical Sections and Testing}

To validate the simulation results, working prototype models of both the concentrator and diffuser were fabricated using the optimal values of the convergence/divergence angles and tested in a laboratory environment.

\subsection{Fabrication of the Prototypes}

Even though the concentrator had optimum convergence angles of $11.5^{\circ}$ for velocity and $10.5^{\circ}$ for power, the working model of the concentrator was fabricated with an $11^{\circ}$ convergence angle. The optimization curves shown in Figure $11 \mathrm{a}, \mathrm{b}$ show that an $11^{\circ}$ convergence angle, the velocity and power variations were still close to optimum, and errors due to this slight deviation were negligible.

Similarly, for the diffuser, the optimum divergence angle was $4.5^{\circ}$ for the velocity variation and $3.6^{\circ}$ for the power variation, so the prototype diffuser was fabricated with a $4^{\circ}$ divergence angle. The optimization curves in Figure 11a,b show that at a $4^{\circ}$ divergence angle, the velocity and power variations were still close to optimum, and errors due to this slight deviation were negligible. The technical specifications for the prototypes of both the concentrator and diffuser are given in Table 6 . The fabricated models were installed and tested in a laboratory environment, as shown in Figure 12. 
Table 6. Technical specifications of the fabricated models of the diffuser and concentrator.

\begin{tabular}{|c|c|c|c|}
\hline S. No & Item Description & Diffuser & Concentrator \\
\hline 1 & Overall length & $1000 \mathrm{~mm}$ & $1000 \mathrm{~mm}$ \\
\hline 2 & Overall diameter & $1000 \mathrm{~mm}$ & $1000 \mathrm{~mm}$ \\
\hline 3 & Angle of conical section & $4^{\circ}$ divergence & $11^{\circ}$ convergence \\
\hline 4 & Frame material & $6 \mathrm{~mm} \times 25 \mathrm{~mm} \mathrm{GI}^{*}$ & $6 \mathrm{~mm} \times 25 \mathrm{~mm} \mathrm{GI}$ \\
\hline 5 & Overall covering material & $2 \mathrm{~mm}$ thick $\mathrm{Al}$ ** & $2 \mathrm{~mm}$ thick $\mathrm{Al}$ \\
\hline 6 & Location of $\mathrm{Al}$ covering *** & Outside GI frame & Inside GI frame \\
\hline 7 & Yaw mechanism & Provided & Provided \\
\hline 8 & Mounting & 75 mm GI pipe & 75 mm GI pipe \\
\hline 9 & Joints with smooth heads & Rivetted joints & Rivetted joints \\
\hline
\end{tabular}
inside the concentrator, a smooth surface was ensured inside by placing the Al covering inside the GI frame of the concentrator. For the same reason, the Al covering was provided outside the GI frame of the diffuser.

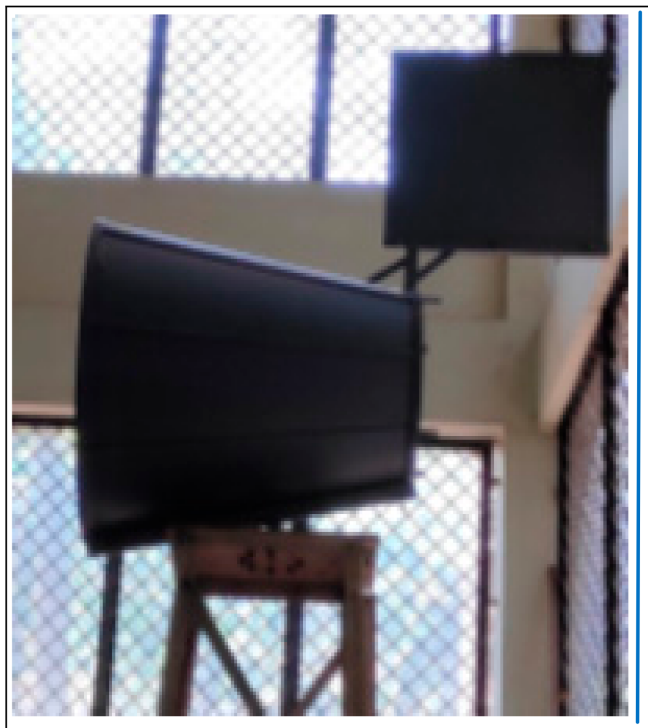

(a)

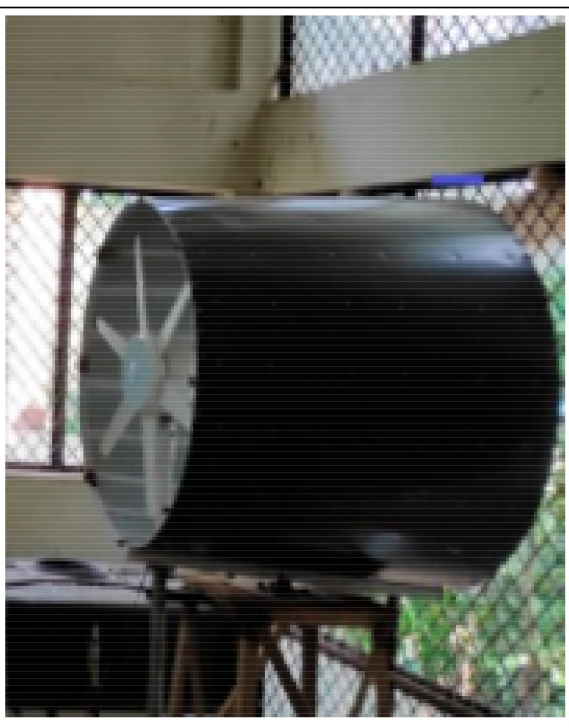

(b)

Figure 12. (a) Concentrator and (b) diffuser, mounted for testing.

\subsection{Testing of the Prototype}

Figure 13 shows the test setup arranged for testing of the prototype models. Figure 13a-c indicate the dimensions of the wind turbine, diffuser, and concentrator, respectively. The wind simulation laboratory was equipped with a flexible wind setup that was controlled through a variable frequency drive (VFD), as shown in Figure 13d. The VFD enabled a smooth variation of the wind velocity over the test range of $1 \mathrm{~m} / \mathrm{s}$ to $15 \mathrm{~m} / \mathrm{s}$.

The inlet wind velocity was measured at the geometric centers of eight equal sectors of a circle of diameter ' $d$ ' and at the center of the circle itself, where ' $d$ ' was equal to the diameter of the inlet of the conical section. This imaginary circle was placed on a plane, midway between the wind generation unit and the conical section inlet, and perpendicular to the direction of flow of wind; the center of the circle lay on the line passing through the centers of the wind-generating unit and the conical section inlet, as shown in Figure 14a. These nine measurement locations were as shown in Figure 14d. The average of these nine readings was taken as the inlet velocity. The outlet velocity was measured on a plane close to the inlet of the diffuser, and the plane close to the outlet of the concentrator, as respectively shown in Figure 14b,c. The outlet velocity was calculated as the average of eight velocities measured at the geometrical centers of eight equal-area sectors of the inlet/outlet circles, as explained for the inlet velocity. The ninth reading at the center of the circle was not taken, as the location was just in front of the wind turbine fulcrum. 


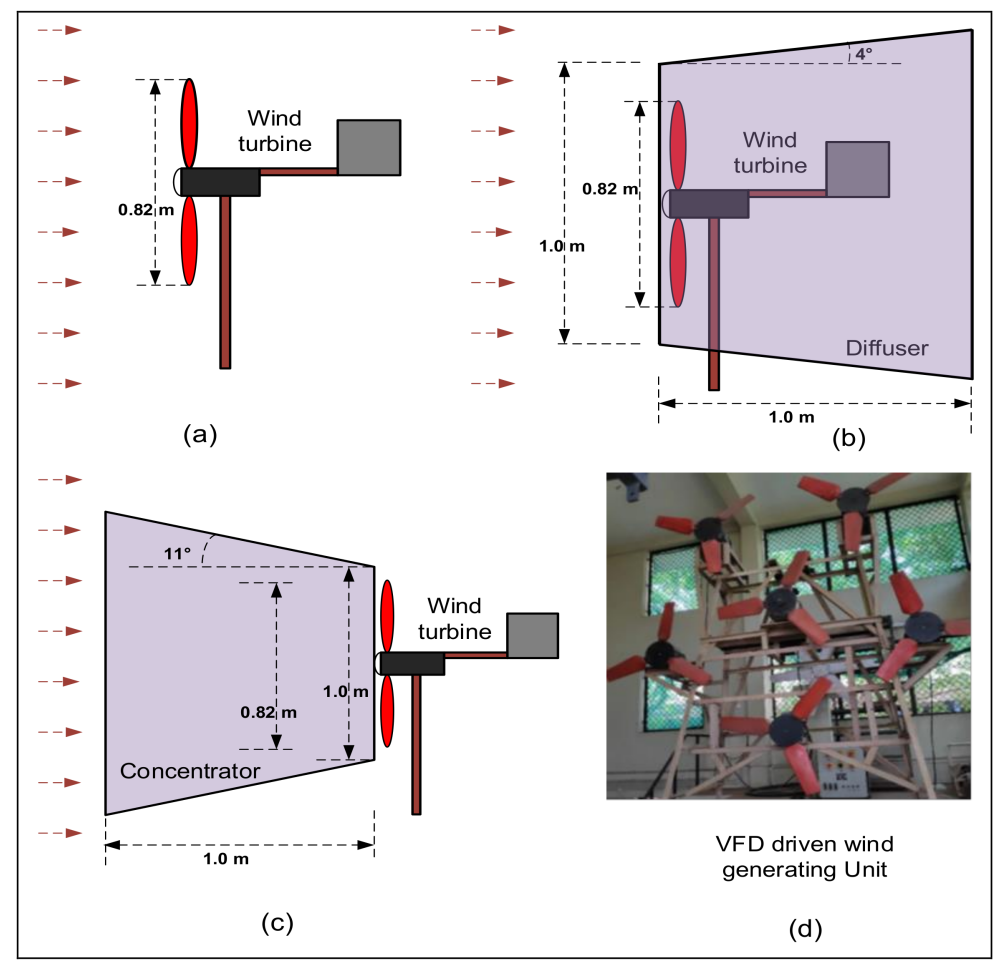

Figure 13. (a-c) Dimensional drawings of practical test setup; (d) The VFD wind generator.

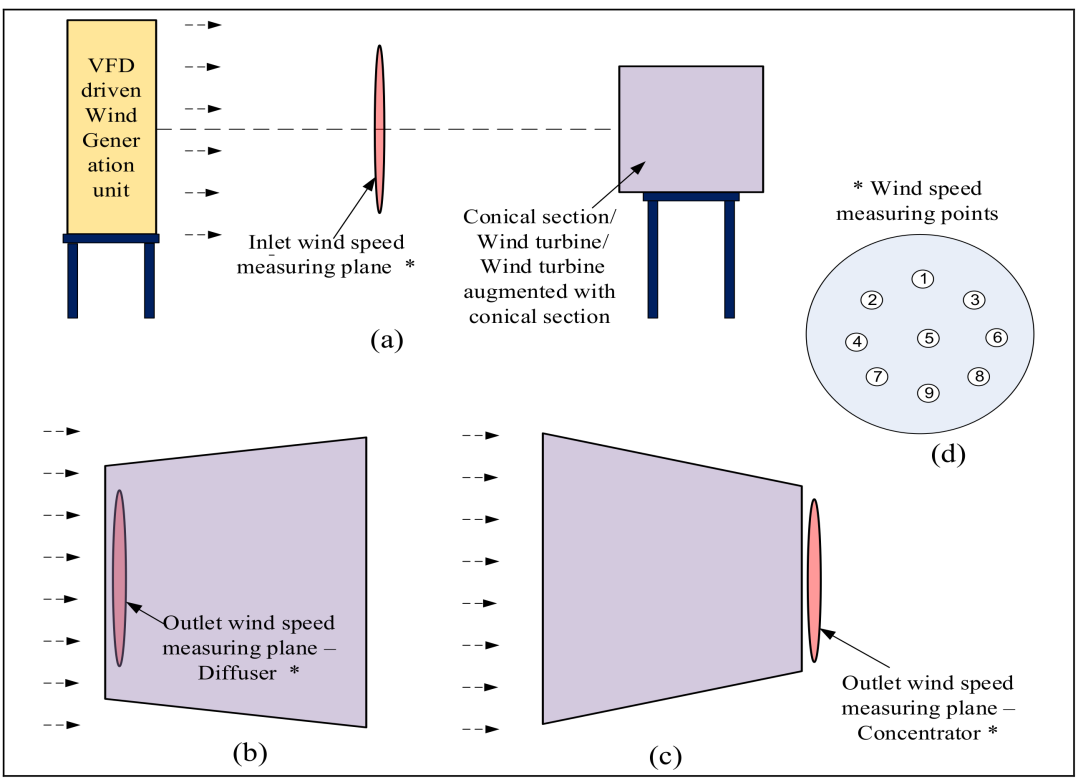

Figure 14. Measurement locations of wind velocity: (a) inlet; (b) outlet diffuser; (c) outlet concentrator. (d) Measurement points in the selected plane.

The measurement of the wind velocity, the most critical parameter of this study, was carried out with maximum care to ensure accuracy of the study. Obtaining an area average wind velocity requires multiple measurements, and determining their average. However, practical limitations apply to the number of measurements that can be taken during an experiment.

\subsection{Measurement of Wind Velocity Variations}

Wind velocity variations were computed from the measured values as explained above. A comparison of the measured wind velocity variations with those of the simulation 
results is shown in Figure 15. The measurements carried out on the fabricated models validated the simulation results.

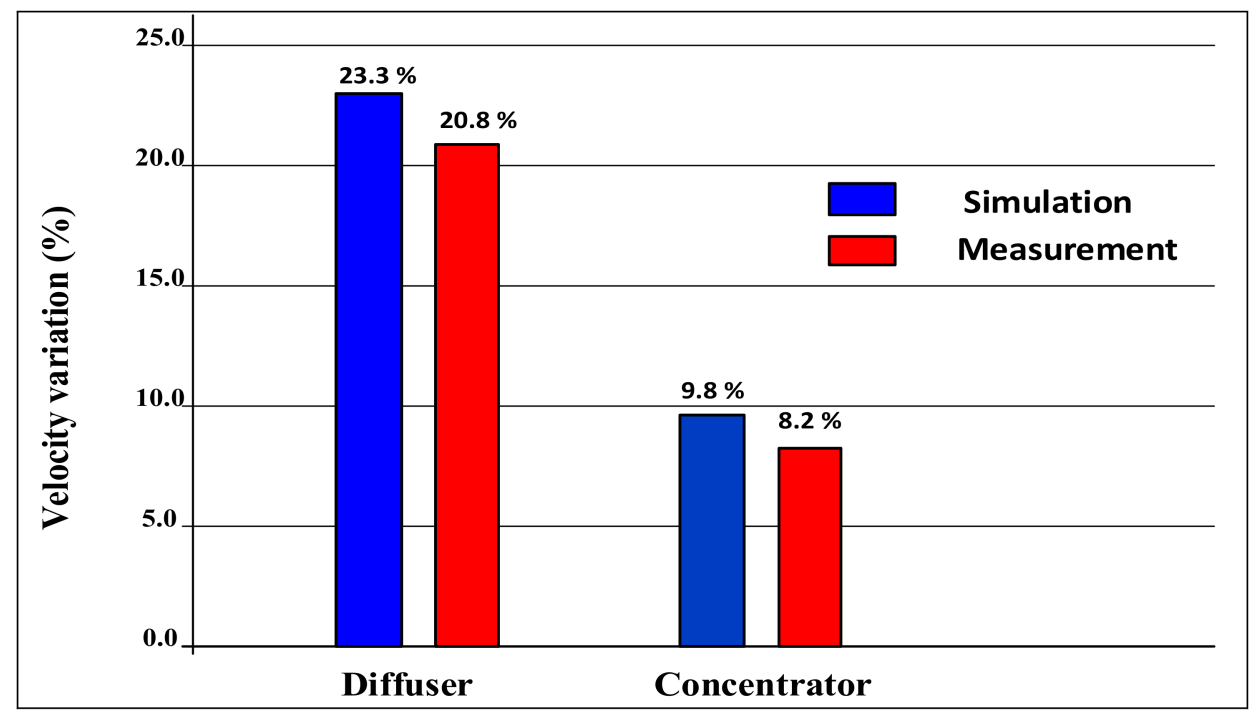

Figure 15. Comparison of velocity variations.

\subsection{Measurement of Power Variations}

Performance of the conical sections regarding power output was verified by comparing the power outputs of the wind turbine with and without the conical sections. A small $24 \mathrm{~V}$ DC wind turbine that was $820 \mathrm{~mm}$ in diameter and had a rated speed of $12 \mathrm{~m} / \mathrm{s}$ and a $100 \mathrm{~W}$ capacity was used for the test; its performance characteristics are shown in Figure 16.

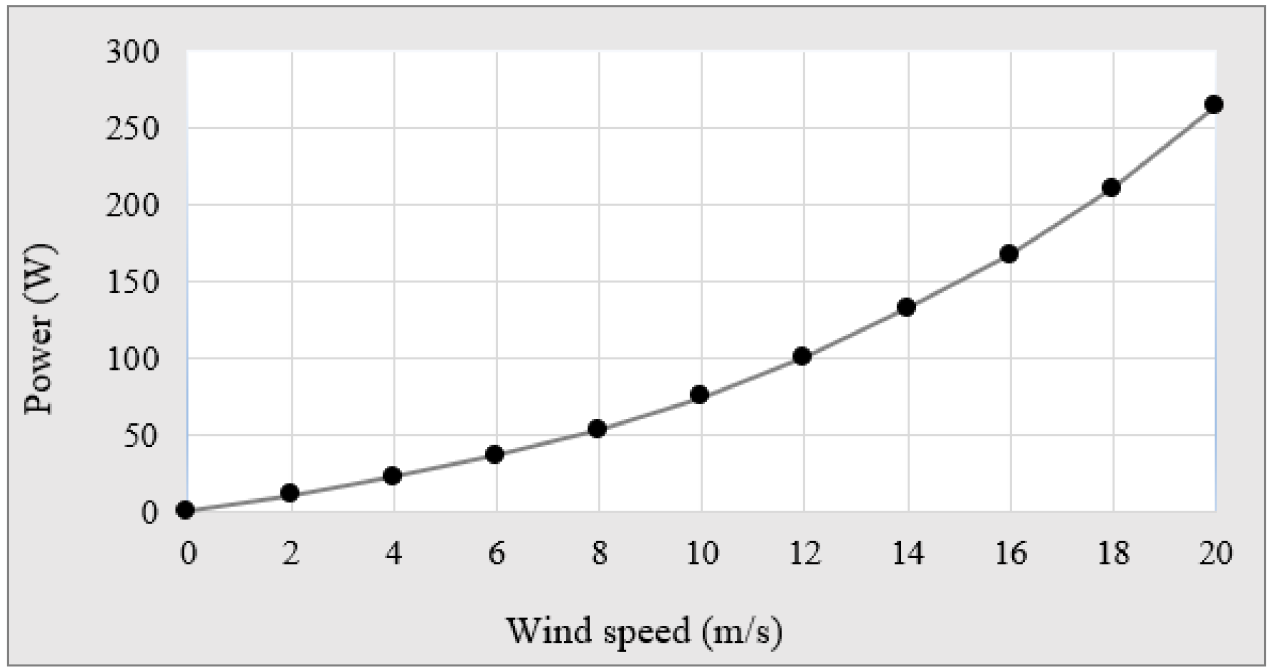

Figure 16. Performance characteristics of the wind turbine (M300).

The wind turbine's output power was measured with a watt meter. A $500 \mathrm{~W}$ rheostat was used as the test load. A voltmeter and ammeter were used for monitoring the voltage and current output. Inlet wind velocities were measured with an anemometer, as explained earlier in Figure 14d.

Arrangements for testing and measurements are illustrated in the schematic diagrams shown in Figure 17a (wind turbine alone), Figure 17b (wind turbine augmented with the diffuser), and Figure 17c (wind turbine augmented with the concentrator). All three groups of tests were carried out with same inlet wind velocities. The power output was measured and recorded for each of the three cases at various inlet wind velocities. Taking the power output of the test condition 'wind turbine alone' as the base, the percentage variations were 
calculated for both the diffuser-augmented WT and the concentrator-augmented WT for each wind velocity applied. The average of these percentage variations in both cases were taken as the power variation percentages.

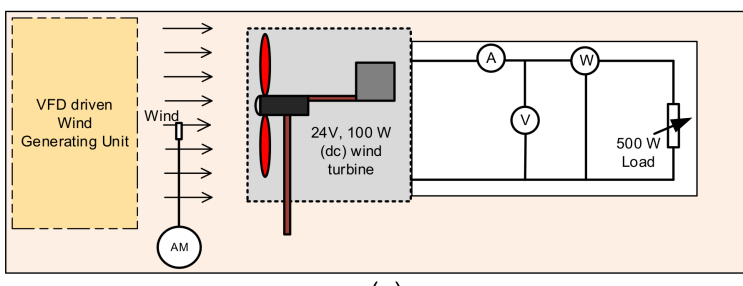

(a)

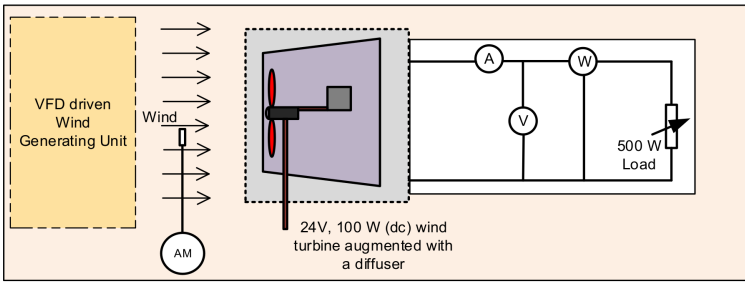

(b)

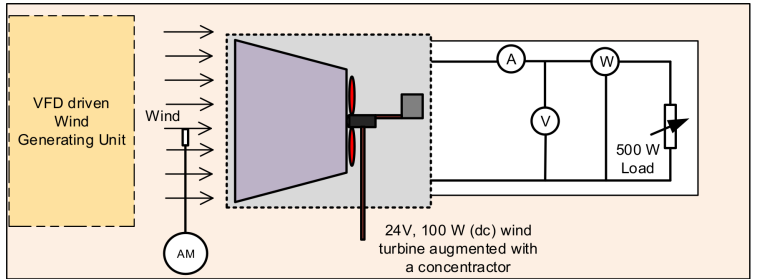

(c)

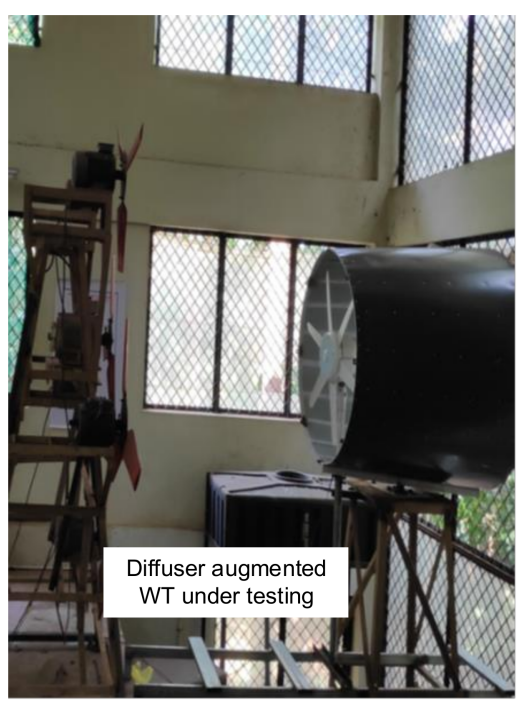

(d)

$V$ - Voltmeter
A - Ammeter

A - Ammeter
$W$ - Wattmeter

AM - Anemometer

Figure 17. The arrangement for the output-power measurements. (a) WT; (b) DAWT; (c) CAWT; (d) DAWT during testing.

The power variation percentage obtained for both the diffuser and concentrator are shown in Figure 18. It can be seen that under similar operating conditions and dimensions, the diffuser attained a maximum recoverable power improvement of $+63.2 \%$, compared to $11.1 \%$ for the concentrator. Both of these power improvements were attained at their respective optimum divergence/convergence angles. The experimental results ratified the simulation results.

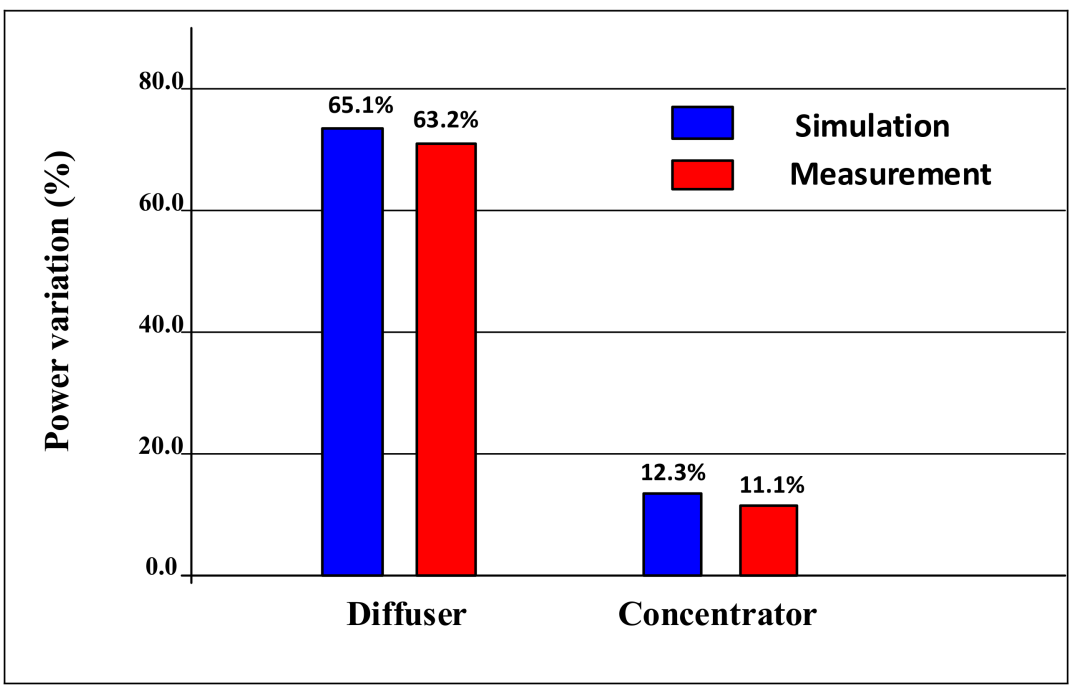

Figure 18. A comparison of the power variations. 
The above analysis suggests that diffusers are better choice for wind velocity/power improvement applications for open flows like natural winds. The divergence angle of the diffuser and position of the wind turbine within the diffuser affect the output velocity/power. For optimum velocity/power, the wind turbine should be placed close to the inlet within the optimum diffuser (i.e., the diffuser having the optimum divergence angle).

\subsection{Error Analysis}

As shown in Figures 15 and 18, the simulation results and test results were closely comparable. However, the test results were slightly on the lower side compared to the simulation results. For the diffuser, the velocity variation (\%) between the simulation results $(23.3 \%)$ and test results $(20.8 \%)$ was $2.5 \%$. This meant that when a $10 \mathrm{~m} / \mathrm{s}$ inlet velocity was applied to the diffuser, the simulation predicted a wind velocity improvement to $12.33 \mathrm{~m} / \mathrm{s}$, and a practical measurement with the prototype diffuser indicated only $12.08 \mathrm{~m} / \mathrm{s}$.

Velocity measurements using an anemometer are prone to errors from alignment and orientation. Since nine measurements were involved in every single reading, even slight variations in individual measurements could add up to some residual errors. Maximum care was taken to reduce such errors during measurements. In addition, anemometer mounting structures slightly alter the wind flow pattern, which causes another small, unavoidable error. Natural crosswinds, even though care was taken to minimize them, can have some influence on velocity measurements as well. The wall behind the turbine, the person taking the reading, and the turbine structure itself create obstacles to the wind flow, and can contribute some errors in practical measurements.

\section{Conclusions}

It is evident from the deliberations above that, when placed in an open flow of wind, conical sections can improve the velocity and extractable power of wind. Conical sections can be operated in either a concentrator or diffuser mode for this purpose. This paper established that a one-meter diffuser with an approximately $4^{\circ}$ divergence angle enhanced wind velocity by $23.3 \%$ when it was placed in an open flow of wind. This enhancement was achieved by optimizing the divergence angle alone. A conventional HAWT, when augmented with such a diffuser, showed an output power boosted by $65.1 \%$. This enables a DAWT to penetrate more into the lower side of the wind velocity spectrum. These findings were in agreement with previous studies; and reconfirmed that a DAWT can exceed the Betz limit of the power coefficient (59\%).

A conical section in concentrator mode or diffuser mode works using different mechanisms. However, the velocity variation and power variation are related to their respective convergence/divergence angles, whereas the values of the optimum convergence/divergence angles are different for the diffuser and concentrator modes. Velocity and power variation through a conical section can be expressed in terms of their convergence (divergence) angles, as expressed in Equations (2)-(5).

Our analysis confirmed that the diffuser mode was preferred over the concentrator mode due to the higher output power delivered. This higher output power was achieved due to the enhanced wind flow created by the low pressure inside the diffuser. Another reason for preferring the diffuser is that the optimum angle was $3.6^{\circ}$ for the diffuser compared to the concentrator. This lower optimum angle resulted in lower horizontal wind loads on the WT tower and lesser distortion of the downstream winds.

Author Contributions: Conceptualization, J.N.M.; methodology, J.N.M., K.S. and A.S.; software, J.N.M.; validation, J.N.M. and K.S.; formal analysis, J.N.M.; investigation, J.N.M.; resources, A.S.; data curation, J.N.M., K.S. and A.S.; writing-original draft preparation, J.N.M. and K.S.; writingreview and editing, K.S. and A.S.; supervision, K.S. and A.S. All authors have read and agreed to the published version of the manuscript.

Funding: This work was supported by the project Young Faculty Research Fellowship (YFRF) [DIC/MUM/GA/10(37)D] Ministry of Electronics \& Information Tech., Govt. of India. 
Institutional Review Board Statement: Not applicable.

Informed Consent Statement: Not applicable.

Data Availability Statement: This study did not report any data.

Conflicts of Interest: The authors declare no conflict of interest.

\section{References}

1. Harjanne, A.; Korhonen, J. Abandoning the concept of renewable energy. Energy Policy 2019, 127, 330-340. [CrossRef]

2. BP Statistical Review of World Energy. Available online: http://www.indiaenvironmentportal.org.in/files/file/bp-stats-review2018-full-report.pdf (accessed on 3 April 2019).

3. Mytilinou, V.; Kolios, A.; Lorenzo, G. A comparative multi-disciplinay policy review in wind energy developments in Europe. Int. J. Sustain. Energy 2015, 36, 754-774. [CrossRef]

4. Mazarbhuiya, H.; Biswas, A.; Sharma, K. Blade thickness effect on the aerodynamic performance of an asymmetric NACA six series blade vertical axis wind turbine in low wind speed. Int. J. Green Energy 2020, 17, 171-179. [CrossRef]

5. Xydis, G. A Wind Resource Assessment around Large Mountain Masses-The Speed-Up Effect. Int. J. Green Energy 2015, 13, 616-623. [CrossRef]

6. Wen, C.; Zhang, J.; Wang, C.; Dong, X.; Peng, H.; Gao, X.; Wang, J. An analysis method for exergy efficiency of wind turbines based on experiment and simulation. Energy Sources Part A Recovery Util. Environ. Eff. 2020, 42, 1072-1084. [CrossRef]

7. Bahramiasl, S.; Abbaspour, M.; Karimirad, M. Experimental study on gyroscopic effect of rotating rotor and wind heading angle on floating wind turbine responses. Int. J. Environ. Sci. Technol. 2018, 15, 2531-2544. [CrossRef]

8. Hansen, K.; Mathiesen, B.; Skov, I. Full energy system transition towards 100\% renewable energy in Germany in 2050. Renew. Sustain. Energy Rev. 2019, 102, 1-13. [CrossRef]

9. Zappa, W.; Junginger, M.; Broek, M. Is a 100\% renewable European power system feasible by 2050? Appl. Energy 2019, 233-234, 1027-1050. [CrossRef]

10. Hall, C.; Lambert, J.; Balogh, S. EROI of different fuels and the implications for society. Energy Policy 2014, 64, 141-152. [CrossRef]

11. Lambert, J.; Hall, C.; Balogh, S.; Gupta, A.; Arnold, M. Energy, EROI and quality of life. Energy Policy 2014, 64, 153-167. [CrossRef]

12. Gielen, D.; Boshell, F.; Saygin, D.; Bazilian, M.; Wagner, N.; Gorini, R. The role of renewable energy in the global energy transformation. Energy Strategy Rev. 2019, 24, 38-50. [CrossRef]

13. Abbaspour, M.; Radmanesh, A.; Soltani, M. Unsteady flow over offshore wind turbine airfoils and aerodynamic loads with computational fluid dynamic simulations. Int. J. Environ. Sci. Technol. 2016, 13, 1525-1540. [CrossRef]

14. Mukhopadhyay, R.; Karisiddaiah, S. Landscapes and Landforms of India; Springer: Berlin/Heidelberg, Germany, 2014; pp. 91-101. [CrossRef]

15. Bureau of Energy Efficiency; New and Renewable Energy Sources (NRES). General Aspects of Energy Management and Energy Audit, 4th ed.; BEE, Government of India: New Delhi, India, 2015; Volume 1, p. 271.

16. Global Wind Atlas. Available online: https://globalwindatlas.info (accessed on 15 July 2021).

17. Abbaspour, M.; Shojaee, M. Innovative approach to design a new national low velocity wind tunnel. Int. J. Environ. Sci. Technol. 2009, 6, 23-34. [CrossRef]

18. Matsushima, T.; Takagi, S.; Muroyama, S. Characteristics of a highly efficient propeller type small wind turbine with a diffuser. Renew. Energy 2006, 31, 1343-1354. [CrossRef]

19. Kannan, T.; Mutasher, S.; Lau, Y. Design and flow velocity simulation of diffuser augmented wind turbine using CFD. J. Eng. Sci. Technol. 2013, 8, 372-384.

20. Orosa, J.; García-Bustelo, E.; Oliveira, A. An Experimental Test of Low Speed Wind Turbine Concentrators. Energy Sources Part A Recovery Util. Environ. Eff. 2012, 34, 1222-1230. [CrossRef]

21. Gohar, G.; Manzoor, T.; Ahmad, A.; Hameed, Z.; Saleem, F.; Ahmad, I.; Sattar, A.; Arshad, A. Design and comparative analysis of an INVELOX wind power generation system for multiple wind turbines through computational fluid dynamics. Adv. Mech. Eng. 2019, 11, 1-10. [CrossRef]

22. Korprasertsak, N.; Leephakpreeda, T. CFD-Based Power Analysis on Low Speed Vertical Axis Wind Turbines with Wind Boosters. Energy Procedia 2015, 79, 963-968. [CrossRef]

23. Promdee, C.; Photong, C. Effects of Wind Angles and Wind Speeds on Voltage Generation of Savonius Wind Turbine with Double Wind Tunnels. Procedia Comput. Sci. 2016, 86, 401-404. [CrossRef]

24. Akyürek, B.; Türkay, B. The prediction and penetration of wind energy with storage system analysis. Energy Sources Part B Econ. Plan. Policy 2017, 12, 211-215. [CrossRef]

25. Shonhiwa, C.; Makaka, G. Concentrator Augmented Wind Turbines: A review. Renew. Sustain. Energy Rev. 2016, 59, 1415-1418. [CrossRef]

26. Vaz, J.; Wood, D. Effect of the diffuser efficiency on wind turbine performance. Renew. Energy 2018, 126, 969-977. [CrossRef]

27. Yan, C.; Archer, C. Assessing compressibility effects on the performance of large horizontal-axis wind turbines. Appl. Energy 2018, 212, 33-45. [CrossRef] 